Article

\title{
Lysine Propionylation is a Widespread Post-Translational Modification Involved in Regulation of Photosynthesis and Metabolism in Cyanobacteria
}

\author{
Mingkun Yang ${ }^{1,+}\left(\mathbb{D}\right.$, Hui Huang ${ }^{1,2,+}$ and Feng Ge ${ }^{1, *(\mathbb{D})}$ \\ 1 Key Laboratory of Algal Biology, Institute of Hydrobiology, Chinese Academy of Sciences, \\ Wuhan 430072, China \\ 2 University of Chinese Academy of Sciences, Beijing 100039, China \\ * Correspondence: gefeng@ihb.ac.cn; Tel.: +86-2768-78-0500 \\ + These authors have contributed equally to this work.
}

Received: 18 July 2019; Accepted: 16 September 2019; Published: 26 September 2019 updates

\begin{abstract}
Lysine propionylation is a reversible and widely distributed post-translational modification that is known to play a regulatory role in both eukaryotes and prokaryotes. However, the extent and function of lysine propionylation in photosynthetic organisms remains unclear. Cyanobacteria are the most ancient group of Gram-negative bacteria capable of oxygenic photosynthesis, and are of great importance to global carbon and nitrogen cycles. Here, we carried out a systematic study of lysine propionylaiton in cyanobacteria where we used Synechocystis sp. PCC 6803 (Synechocystis) as a model. Combining high-affinity anti-propionyllysine pan antibodies with high-accuracy mass spectrometry (MS) analysis, we identified 111 unique lysine propionylation sites on 69 proteins in Synechocystis. Further bioinformatic analysis showed that a large fraction of the propionylated proteins were involved in photosynthesis and metabolism. The functional significance of lysine propionylation on the enzymatic activity of fructose-1,6-bisphosphatase (FbpI) was studied by site-directed mutagenesis and biochemical studies. Further functional studies revealed that the propionylation level of subunit II of photosystem I (PsaD) was obviously increased after high light (HL) treatment, suggesting that propionylation may be involved in high light adaption in Synechocystis. Thus, our findings provide novel insights into the range of functions regulated by propionylation and reveal that reversible propionylation is a functional modification with the potential to regulate photosynthesis and carbon metabolism in Synechocystis, as well as in other photosynthetic organisms.
\end{abstract}

Keywords: lysine propionylation; post-translational modification; Synechocystis sp. PCC 6803; cyanobacteria; fructose-1,6-bisphosphatase; PsaD; proteomic analysis

\section{Introduction}

Lysine propionylation is a reversible and widely distributed post-translational modification (PTM) in which a propionyl group $\left(\mathrm{CH}_{3}-\mathrm{CH}_{2}-\mathrm{CO}\right)$ is added to the $\epsilon$-amino group of lysine residue on a protein moiety [1,2]. Pioneering work by Zhao et al. opened new avenues to identify lysine propionylation events in both histone and non-histone protein substrates around ten years ago [1,2]. Comprehensive studies have focused on identifying the propionylated proteins in Thermus thermophilus [3], Mycobacterium tuberculosis [4], yeast [5], mammalian cells [1,6], and mouse liver mitochondria [7], as well as the enzymes that are responsible for adding and removing this modification, including p300 [1,2,6], CREB-binding protein [1,2], Sirt1 [1], Sirt2 [6,8], Sirt3 [8], Pat [8], AcuA [8], and CobB [8]. These studies have demonstrated that lysine propionylation occurs in a diverse range of proteins and exerts influence 
on a wide range of biological functions. In particular, lysine propionylation contributes to the overall metabolic regulatory network and cellular stress responses in mice [7]. It can regulate the enzyme activities of propionyl-CoA synthetase in Salmonella enterica [8] and isocitrate lyase (Icl) in M. tuberculosis [4]. These findings strongly suggest that lysine propionylation is likely to be one of the mechanisms that regulates cellular metabolism and responds to stress conditions in both bacteria and mammals [3,7].

Cyanobacteria are the most ancient group of Gram-negative bacteria capable of oxygenic photosynthesis that exhibit extraordinary diversity in terms of morphology and cell activity [9]. They are of global importance for $\mathrm{CO}_{2}$ assimilation, $\mathrm{O}_{2}$ production, and $\mathrm{N}_{2}$ fixation [10]. Cyanobacteria are ancient life forms believed to be the progenitors of higher plant chloroplasts [11]. The photosynthetic activity of cyanobacteria is responsible for approximately half of marine primary production and a quarter of global primary production on Earth [12]. Consequently, there are established model organisms for the study of their photosynthetic mechanisms. The unicellular cyanobacterium Synechocystis sp. PCC 6803 (henceforth referred to as Synechocystis) is the first phototrophic organism to undergo full genome sequencing, and has been universally used as a model cyanobacterium in studies about the photosynthetic process and biofuel production [13-15]. Photosynthesis and carbon metabolism are two interrelated processes in photosynthetic organisms [16-18], and complicated mechanisms have evolved to coordinate and regulate multiple pathways involved in the photosynthetic processes and cellular metabolism in cyanobacteria [18-20]. It is crucial to understand the regulatory mechanism between photosynthetic pathways and metabolic processes systematically. Lysine propionylation has been reported to be a functional PTM that contributes to the overall metabolic regulatory network and controls the activities of a set of metabolic enzymes in bacteria $[1,3,8]$; therefore, we hypothesized that lysine propionylation may be involved in the regulation of photosynthesis and carbon metabolism in cyanobacteria. However, to the best of our knowledge, no propionylated proteins have been reported previously in any photosynthetic organism, presenting a major obstacle to understanding the functions of lysine propionylation in cyanobacteria.

To obtain a comprehensive understanding of lysine propionylation in cyanobacteria, a systematic study of propionylation events was performed in Synechocystis. Combining high-affinity anti-propionyllysine pan antibodies with high-accuracy mass spectrometry (MS) analysis and bioinformatics tools, we identified 111 unique lysine propionylation sites on 69 proteins in Synechocystis, out of which 23 propionylated proteins were involved in photosynthesis and respiration, including photosystem I/II subunits, phycocyanin subunits, allophycocyanin subunits, and carbon fixation pathways. Our results reveal the widest variety of propionylated proteins in photosynthetic organisms presently available, and offer insights into the functions related to propionylation in cyanobacteria. The functional significance of lysine propionylation on the enzymatic activity of fructose-1,6-bisphosphatase ( $\mathrm{Fbp}$ ) was determined by site-specific mutagenesis and biochemical studies. Further functional studies showed that the propionylation level of subunit II of photosystem I (PsaD) was significantly upregulated after high light (HL) treatment. Thus, our findings reveal novel insights into the regulatory functions of propionylation, suggesting that lysine propionylation is a functional modification with the potential to impact photosynthesis and carbon metabolism.

\section{Results}

\subsection{Identification of Lysine Propionylated Proteins in Synechocystis}

To assess the possible role of protein propionylation in photosynthetic organisms, we surveyed whole cell lysates from Synechocystis for protein propionylation. As shown in Figure 1B, propionylation signals were abundant and likely to be changed for several protein bands in the $10-55 \mathrm{kDa}$ mass range in Synechocystis under different stress conditions. These results implied that lysine propionylation is a widespread protein modification and is likely to be involved in stress responses in Synechocystis.

On the basis of these observations, we characterized the in vivo propionylation event in the model cyanobacterium by combining immunoaffinity enrichment and an MS-based high-throughput 
proteomic approach (Figure 1A). A total of 115 unique propionylated peptides encompassing 111 propionylation sites from 68 proteins were identified with a false discovery rate (FDR) below $1 \%$ for modified peptide in this study. All spectra containing propionylation were manually inspected as previously described [21,22]. Detailed information about all the identified propionylated peptides is listed in Table S1. All the raw data files were submitted to the public PeptideAtlas repository and can be accessed with the identifier PASS00818 (http://www.peptideatlas.org/PASS/PASS00818). The annotated spectra of all propionylated peptides were also deposited in PeptideAtlas and are supplied as the Supplementary Materials. In addition, the overall absolute peptide mass accuracy was 0.5249 parts per million $(\mathrm{ppm})($ standard deviation $=0.4501 \mathrm{ppm})$ and the average peptide score was 95.79 , indicating the high accuracy and reliability of modified peptide data from MS (Figure S1A). Moreover, we also calculated the number of identified modification sites per protein and approximately $39 \%$ of identified proteins were modified by multiple propionylation sites (Figure S1B).

A

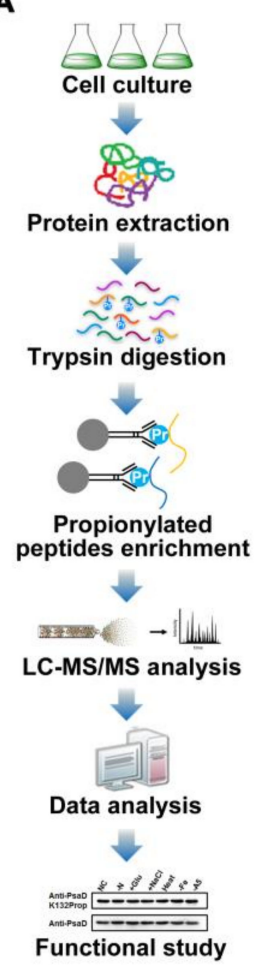

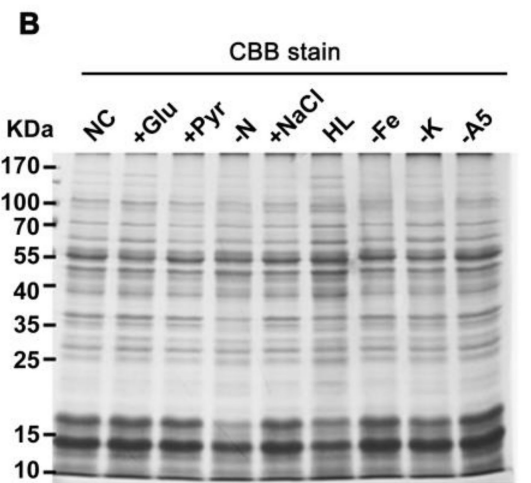

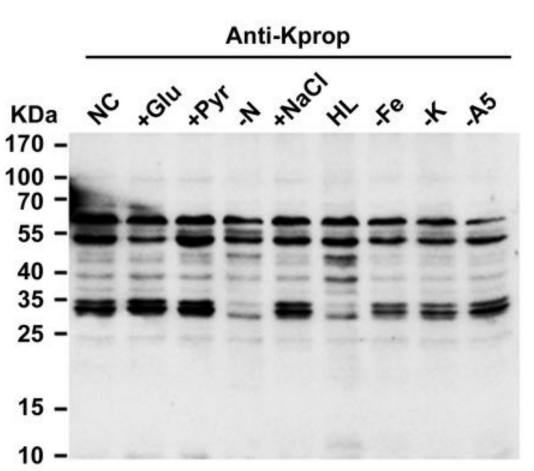

Figure 1. Profiling lysine propionylation in Synechocystis sp. PCC 6803. (A) Flowchart illustrating the experimental procedure for lysine propionylation analysis. (B) Profiling of lysine propionylation in Synechocystis under various stresses. Total proteins $(20 \mu \mathrm{g})$ were extracted from the cells cultured under glucose treatment $(+\mathrm{Glu})$, sodium pyruvate $(+\mathrm{Pyr})$, nitrogen deficiency $(-\mathrm{N})$, sodium chloride $(+\mathrm{NaCl})$, high light (HL) conditions, iron deficiency (-Fe), potassium deficiency (-K), A5 deficiency (-A5), and normal conditions (NC).

\subsection{Functional Annotation of Propionylated Proteins}

To address the functional distribution of identified proteins, we performed a Gene Ontology (GO) functional annotation of all identified proteins according to their biological processes, molecular functions, and cellular compartments (Figure S2A and Table S2). Among the identified proteins, the major biological processes of the propionylated proteins included cellular biosynthetic process (21\%), organic substance biosynthetic process $(20.99 \%)$, and photosynthesis $(17.28 \%)$, indicating that propionylation may play an important role in cellular metabolism. Accordingly, most propionylated proteins were assigned to cytoplasm (31 proteins), followed by the cytoplasmic membrane (14 proteins), periplasm ( 2 proteins) and extracellular matrix (1 protein). However, the subcellular location of 
remaining propionylated proteins (30.4\%) was not predicted. From a molecular function perspective, the propionylated proteins were mostly involved in anion binding $(38.24 \%)$, oxidoreductase activity $(20.59 \%)$, hydrolase activity $(20.59 \%)$, and ribonucleotide binding $(20.59 \%)$. We also predicted lipoproteins and integral membrane proteins, as previous described [23-25]. Among the identified propionylated proteins, nine proteins were detected as integral membrane proteins, with five of the integral membrane proteins having only one transmembrane helix. For the 60 non-integral membrane proteins with propionylation sites, two were grouped to lipoproteins.

To gain further insight into the biological functions of propionylated proteins, we conducted GO, Kyoto Encyclopedia of Genes and Genomes (KEGG) pathway, and protein domain enrichment analyses (Figure 2A and Table S3). The GO enrichment analysis of biological processes showed that the propionylated proteins were mostly enriched in photosynthesis $\left(p=6.50 \times 10^{-6}\right)$. The major molecular functions for propionylated proteins were translation elongation factor activity $\left(p=6.97 \times 10^{-5}\right)$, translation factor activity and nucleic acid binding $\left(\mathrm{p}=3.30 \times 10^{-3}\right)$, and hydrogen ion-transporting ATP synthase activity and rotational mechanisms $\left(p=1.77 \times 10^{-2}\right)$. In cyanobacterial cells, translation of the psbA2 gene, which encodes D1 protein of photosystem II (PSII), is regulated at the elongation step $[26,27]$ and is activated when reducing equivalents are derived from photosystem I [28]. Thus, photosynthesis and protein translation activity are functioned in an interactive and cooperative way [29]. In this scenario, lysine propionylation may be one of the mechanisms to coordinate both processes in cyanobacteria. Future studies should be directed toward a better understanding of the mechanism and physiological significance of propionylation in the regulation of photosynthesis and protein translation.

A

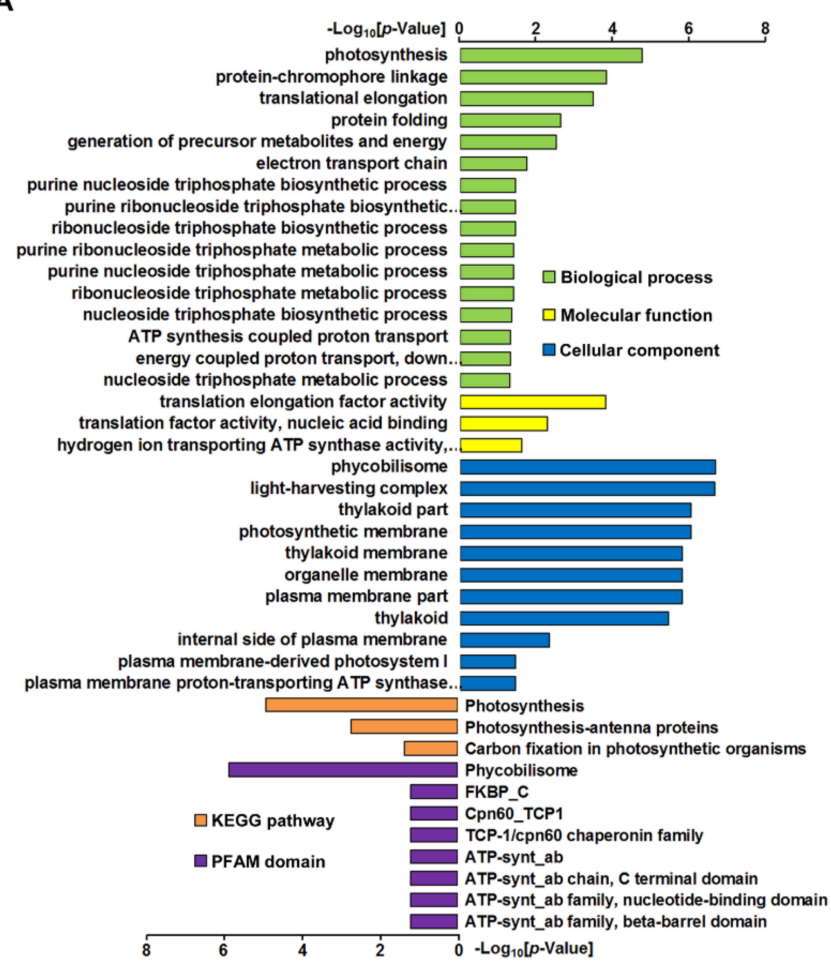

B

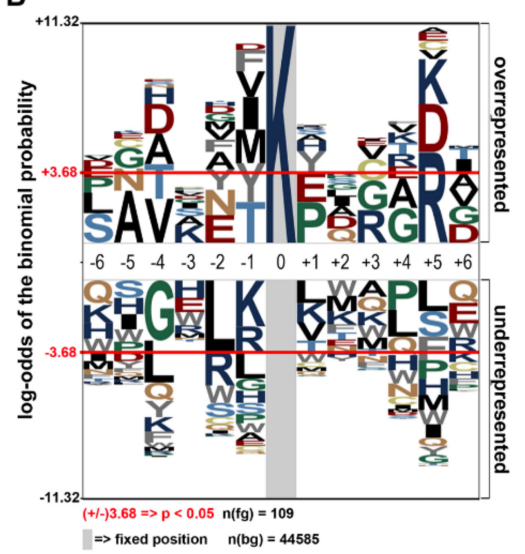

C

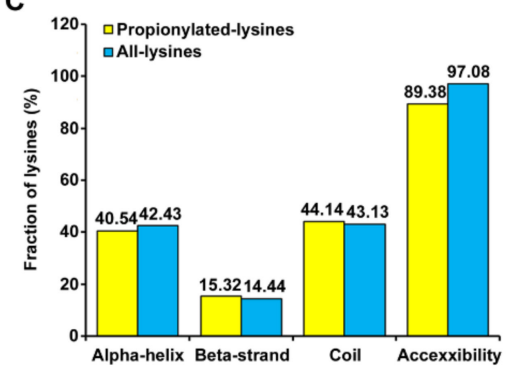

Figure 2. Enrichment analysis of propionylated proteins and bioinformatics analysis of propionylation sites. (A) Histogram representations of the enrichment of propionylated proteins according to their biological processes, molecular functions, cellular components, pathways, and protein family (PFAM) domains. The enrichment of GO categories, pathway, and domain were performed using DAVID bioinformatics tools $(\mathrm{p}<0.05$ ). (B) Sequence properties of lysine propionylation sites. Benjamini-corrected statistical significance values (adjusted $p<0.05$ ) were used to control the family-wide false discovery rate. (C) Probabilities of localization for different secondary structures ( $\alpha$-helix, beta-strand, and coil) and protein surface of identified propionylation sites. 


\subsection{Analysis of Lysine Propionylation Sites}

We further assessed the position-specific amino acid frequencies of the flanking sequences of propionylation sites. The 12 amino acid residues surrounding the lysine propionylation sites were compared with the residues around nonpropionylated lysines from the Synechocystis proteome (Figure 2B). We observed a significant preference of the polar basic residue (arginine) at the +5 position, while propionylation rarely occurred in the nonpolar hydrophobic residue leucine at the -2 position. As the other two amino acid residues (K and D) also showed a relatively high frequency at the +5 position, it was suggested that there may exist three possible site-specific propionylation motifs in Synechocystis, and KxxxxR is most likely to be the one. Further functional experiments are needed to confirm these possible site-specific motifs in Synechocystis.

Next, to elucidate the specific structural properties of propionylation sites, the local secondary structures surrounding propionylation sites were analyzed using NetSurfP software. Consistent with other lysine PTMs [30,31], the propionylated lysine residue was more frequently observed in secondary structure regions. In the present study, more than $55.8 \%$ of propionylated lysine residues were localized in the $\alpha$-helix and $\beta$-strand in comparison to $43.1 \%$ in the coil region. However, the average relative side chain solvent accessibility of propionylated lysines $(89.38 \%)$ was lower than that of all lysines $(97.08 \%)$, as opposed to other lysine PTMs $[30,31]$, indicating that lysine propionylation may have a different effect on modified proteins (Figure $2 \mathrm{C}$ and Table S4).

\subsection{Functional Interaction Networks of Propionylated Proteins in Photosynthesis}

We next generated a protein interaction network of all identified proteins using the Synechocystis protein-protein interaction (PPI) database [32] to assess the physical and functional interactions within our datasets (Figure S3 and Table S5A). Based on this network, protein groups associated with propionylated proteins were characterized, and a large sub-interaction network was further constructed and visualized by Cytoscape. This interaction network consisted of 331 proteins, among which existed 17 propionylated photosynthetic proteins such as allophycocyanin (slr0335, ApcE; slr1986, ApcB; slr2067, ApcA; sll0928, ApcD), phycocyanin (sll1578, CpcA; sll1577, CpcB), ATP synthase (sll1324, AtpF; slr1329, AtpB; sll1326, AtpA), electron transport/Calvin cycle (slr0009, RbcL; slr1643, PetH; slr0364, Pgk), photosystem I (slr1835, PsaB; sll0819, PsaF; slr0737, PsaD), and photosystem II (sll0427, PsbO; sll0851, PsbC) (Figure 3 and Table S5B). As there is little functional information about these interactions, further studies were needed to verify the potential interactions. It is expected that such bioinformatic analysis will contribute to formulating testable hypotheses to explore the function roles of lysine propionylation in Synechocystis, and will be useful in selecting key proteins and possible mechanisms from these proteins. 


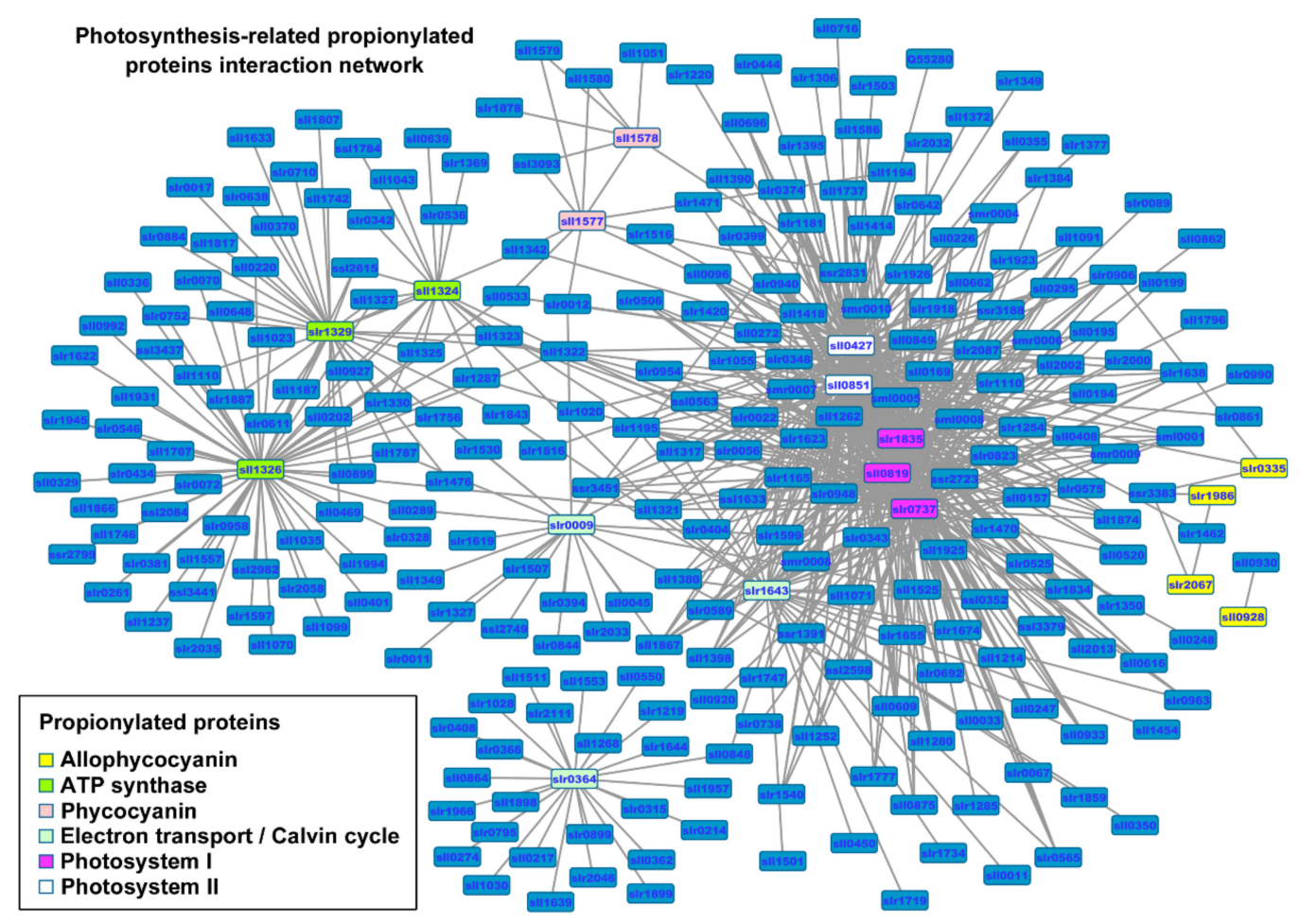

Figure 3. The complete interaction network of identified propionylated proteins associated with photosynthesis in Synechocystis. The propionylated proteins involved in photosynthesis are grouped using associated subcellular localizations and highlighted in different colors.

\subsection{Effects of Propionylation on Metabolic Enzyme Activity}

To determine the molecular pathways in which the propionylated proteins participate, all identified proteins were analyzed and mapped to KEGG pathways of Synechocystis. In accordance with previous studies on lysine propionylation [3], many enzymes involved in metabolic pathways were found to be propionylated in this work, such as enzymes involved in carbon fixation and glycolysis/gluconeogenesis pathways (Table S6 and Figure 4A).

One protein of interest is bifunctional enzyme fructose-1,6/sedoheptulose-1,7-bisphosphatase (FbpI), encoded by slr2094 (Figure 4B). FbpI is the only recognized enzyme in Synechocystis that converts fructose-1,6-biphosphate to fructose-6-biphosphate, a process that is connected with the Calvin cycle, the oxidative photosephosphate cycle, and gluconeogenesis in oxygenic photosynthetic organisms [33]. In this study, two reliable propionylation sites (Lys156 and Lys336) were observed in FbpI (Figure 4C) and the MS/MS spectra of these peptides, indicating the exact sites of their propionylation, are shown in Figure S4A. Multiple sequence alignment analyses revealed that the identified propionylation sites of FbpI were highly conserved in cyanobacteria, suggesting that these residues may be important for an evolutionarily conserved function of FbpI (Figure S4B). To further assess whether lysine propionylation at these positions (Lys156 and Lys336) would affect the enzymatic activity of FbpI, we cloned the slr2094 gene and converted the modified residues at the two positions (Lys156 and Lys336) to arginine (R) to lock protein into a non-propionylated state, as previously described [30]. All mutations were verified by DNA sequencing and MS analysis (Figure S5). The enzymatic activity of FbpI (wild type) and its mutants were then measured. As shown in Figure 4D, in contrast to WT, the mutation of Lys156, Lys336 to R gave rise to a decrease of the enzymatic activity $(p<0.01)$, suggesting that propionylation may alter the enzymatic activity of FbpI. Additionally, based on the crystal structure of FbpI, we found that FbpI could form a stable tetramer and Lys156, Lys336 located in the functional $\alpha$-helix domain and structured loop of FbpI, respectively [34-38] (Figure 4E). Because propionylation changes the charge status of lysine from +1 to 0 and adds a propionyl group to lysine, it is conceivable that propionylation at Lys156 and/or Lys336 is likely to alter the conformation and enzymatic activity of FbpI and further 
affect the cellular metabolic process in Synechocystis. Overall, our results suggest the involvement of lysine propionylation in the regulation of cellular metabolism in Synechocystis, though further in vivo studies are needed to confirm the effects of propionylation on the process of cellular metabolism.

A

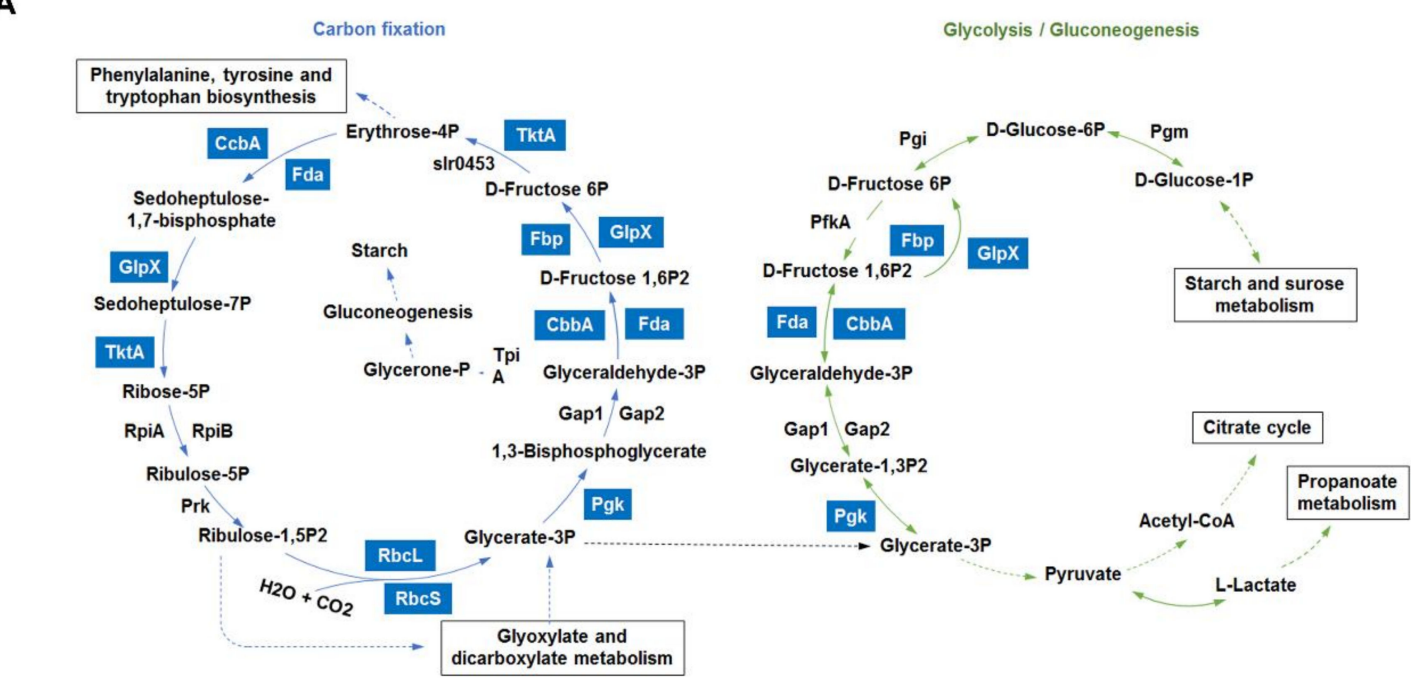

B

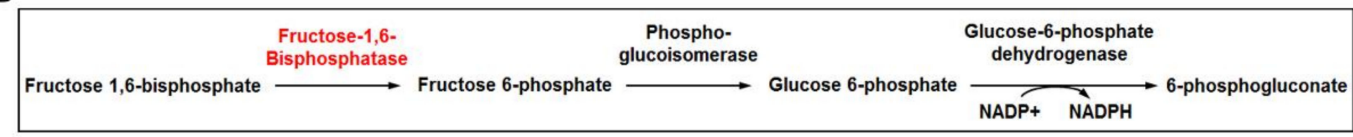

C

\begin{tabular}{cccccc}
\hline Protein & Description & Position & Modified sequence & Score for localization & Localization probability \\
\hline \multirow{2}{*}{ slr2094 } & $\begin{array}{c}\text { fructose-1,6-/ sedoheptulose-1,7- } \\
\text { bisphosphatase (Fbpl) }\end{array}$ & 156 & SATENLK(pr)ILSDCLNR & 72.90 & 1 \\
& 336 & FVDTVHMK(pr)ESPK & 108.56 & 0.98 \\
\hline
\end{tabular}

D

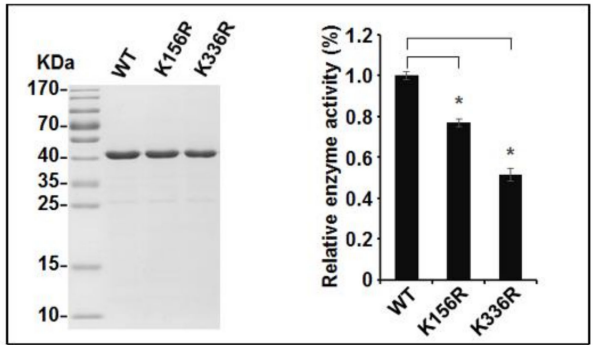

E

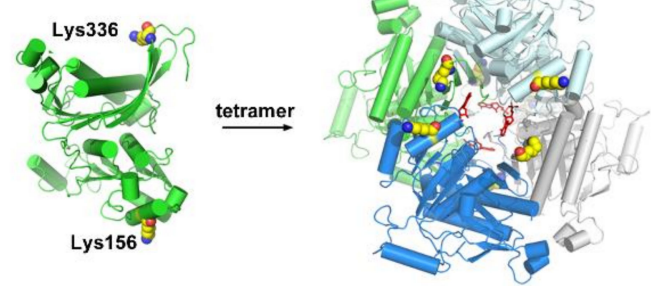

Figure 4. Overview of the lysine propionylation events involved in cellular metabolism in Synechocystis. (A) Working scheme to delineate the lysine propionylation events in carbon metabolism of Synechocystis. The identified propionylated proteins were highlighted in light blue. Solid arrows represent direct reactions and dotted arrows represent reactions with multiple steps. (B) Schematic illustration of the metabolic pathway catalyzed by fructose-1,6/sedoheptulose-1,7-bisphosphatase (FbpI). (C) Identification of the propionylation sites of FbpI. (D) Effects of propionylation sites on the enzyme activity of FbpI. The FbpI and its mutants were expressed and the relative activities were determined. Data are means \pm SD from three independent assays. (E) The crystal structure of FbpI. Two propionylation sites and the structure of the stable tetramer are shown.

\subsection{Validation of Propionylated Proteins Involved in Photosynthesis}

Unique to the photosynthetic organisms, a large proportion of the identified propionylated proteins were involved in photosynthesis. A total of 19 photosynthetic proteins were found to be propionylated (approximately $28 \%$ of the total) according to the mapped KEGG pathways, including a large proportion of the subunits of phycocyanin (CpcA, CpcB, CpcC1, CpcC2, and CpcG1), allophycocyanin (ApcA, 
$\mathrm{ApcB}, \mathrm{ApcD}$, and ApcE), PSII components (PsbC and PsbO), PSI components (PsaB, PsaD, and PsaF), and ATPase complex (AtpA, AtpB, and AtpF) (Figure 5A). Based on this observation, four identified photosynthetic proteins ( $\mathrm{PsaD}, \mathrm{PsbC}, \mathrm{CpcB}$ and $\mathrm{PsbO}$ ) were selected to further validate our MS findings. The presence of four propionylated proteins identified through our proteomic approach was validated by immunoprecipitation and western blotting (Figure 5B). The right part of Figure 5B shows the propionylation level of proteins under different conditions, and the corresponding protein levels of PsaD, PsbC, CpcB, and PsbO are displayed in the left part of Figure 5B. We found that the propionylation level of PsaD was increased in nitrogen deficiency, HL, and glucose conditions, especially under HL. For PsbC, the propionylation status was evidently elevated under HL. For CpcB, the propionylation level was significantly increased under $\mathrm{HL}$ and glucose conditions. For PsbO, the propionylation level was evidently affected under nitrogen deficiency and glucose conditions, and moderately changed under HL. The changes in propionylation statuses of these proteins indicate that propionylation may play regulatory role in response to different environmental stimuli. Further studies are required to reveal how reversible propionylation contributes to the response of Synechocystis to various environmental conditions.

A

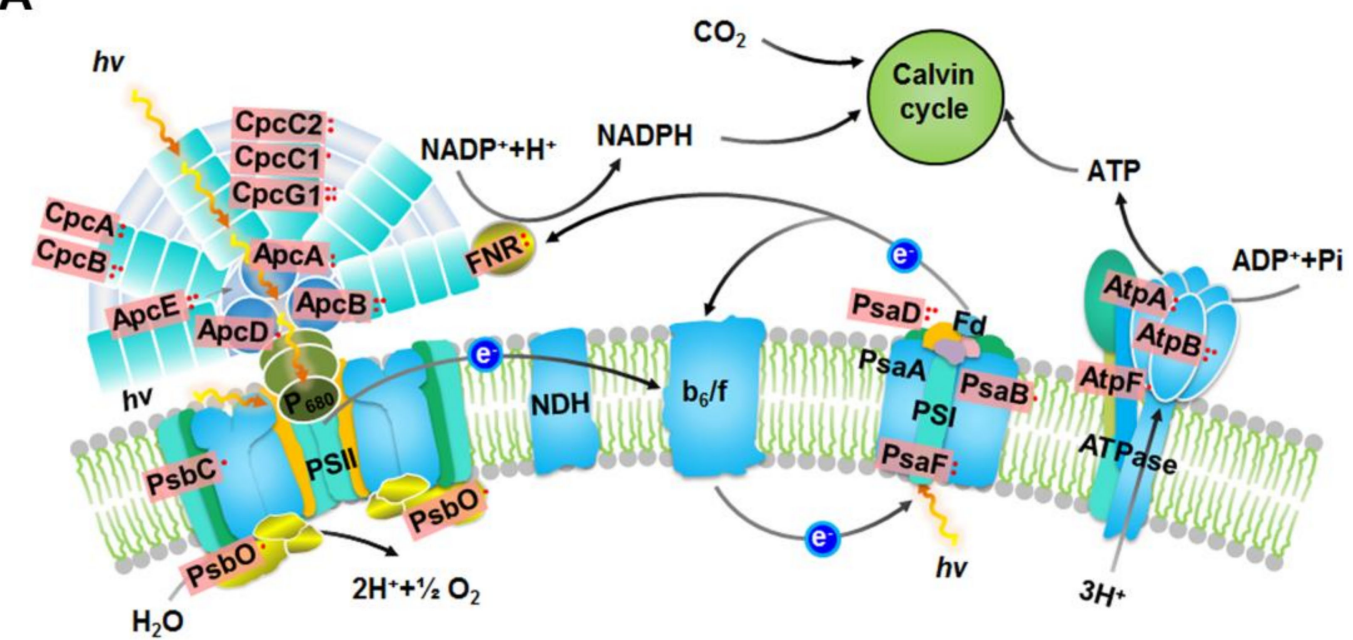

B
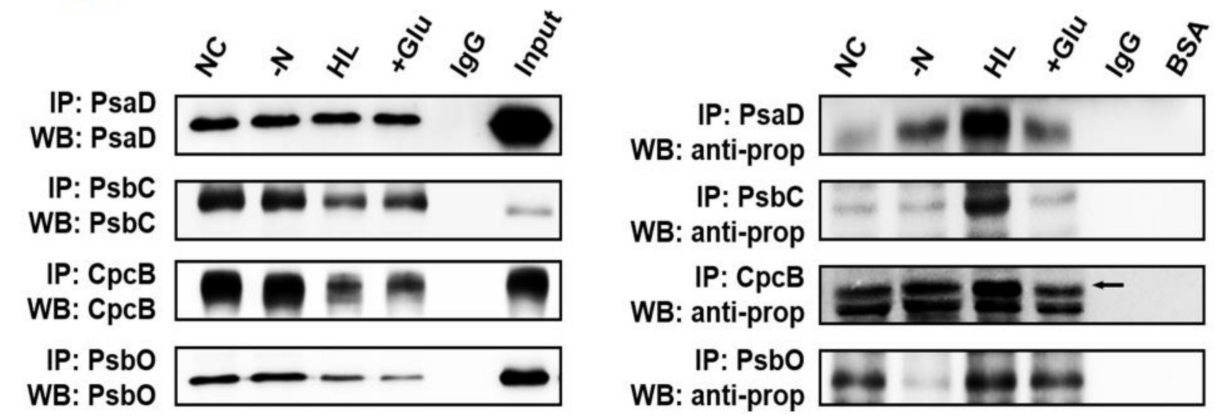

Figure 5. Overview of the lysine propionylation events involved in photosynthesis in Synechocystis. (A) Illustrations of propionylated proteins involved in the photosynthesis process. The identified propionylated proteins are highlighted in light red. (B) Verification of propionylated proteins associated with photosynthesis using immunoprecipitation and western blotting. NC: normal condition, -N: nitrogen deficiency, HL: high light condition, +Glu: glucose condition, Input: total cell lysate. 


\subsection{Increased Propionylation Level of PsaD in High Light Condition}

According to the results of immunoprecipitation and western blotting (Figure 5B), we further assessed the propionylation status of PsaD under different light intensities. By performing western blotting analysis on whole cell lysates with pan anti-propionyllysine antibody, we found that there was only one band (the bottom band in the middle part of Figure 6A) at the position corresponding to the molecular weight of PsaD. Considering that the propionylation level of PsaD was significantly increased under HL (Figure 5B), the band around 14 kDa may represent the signals from the propionated PsaD. By comparing with the corresponding immunoblot signals of PsaD, we can see that the propionylation levels of PsaD were likely to be increased after exposure to HL conditions for $0,6,12,24$, and $36 \mathrm{~h}$. In this study, we identified three reliable propionylation sites (Lys84, Lys107, and Lys132) in PsaD (Figure 6B) and the MS/MS spectra of these peptides, which indicate their exact propionylation sites, are shown in Figure S6. Further analysis revealed that the lysines at positions 84 (in $\beta$-sheet), 107 (in coil), and 132 (in coil) in PsaD were highly conserved from cyanobacteria to plants (Figure 6C). To explore in more detail whether HL treatment might affect the propionylation levels of Synechocystis proteins in vivo, we further evaluated the propionylation status of Lys132 in PsaD with the generated site-specific propionylation antibody. As shown in Figure 6D, the result of dot blot analysis confirmed the specificity of the antibody and the propionylation level at Lys132 in PsaD was significantly increased during the long-term exposure to $\mathrm{HL}$, suggesting that propionylation at this residue may be a novel regulatory mechanism in response to HL stress in Synechocystis. Moreover, western blotting analyses also showed that the propionylation level of PsaD at Lys132 were not affected by other stresses such as nitrogen deficiency, glucose addition, $\mathrm{NaCl}$ addition, heat treatment, iron deficiency, or copper deficiency (Figure S6D). As Lys132 in PsaD is important for the stable association of PsaD to the PSI core [39], our findings suggest that propionylation at this residue may play a role in the regulation of photosynthesis in Synechocystis. 
A
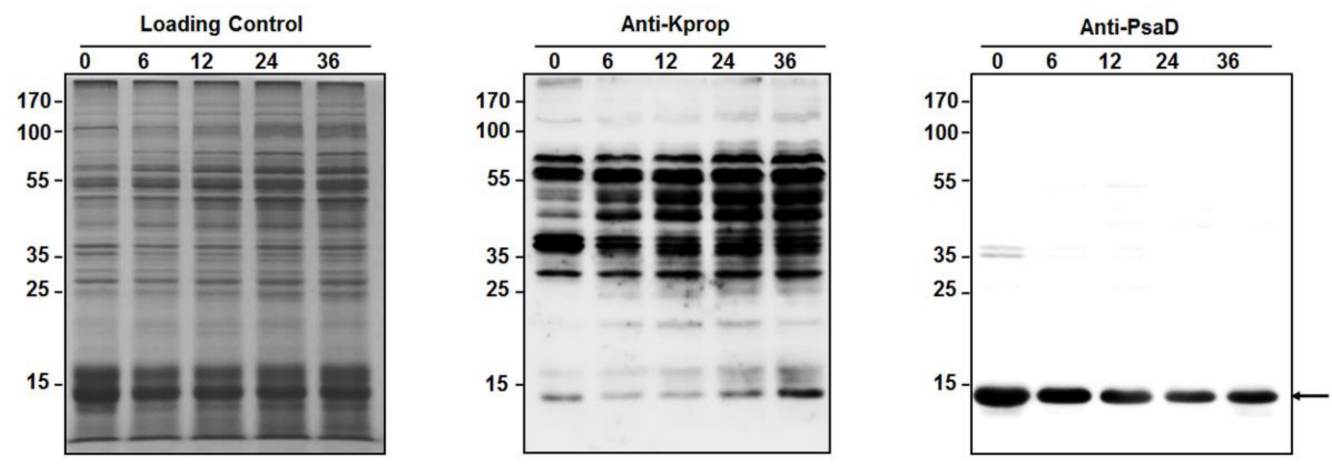

B

\begin{tabular}{|c|c|c|c|c|c|}
\hline Protein & Description & Modified Sequence & Position & Score for Localization & Localization Probability \\
\hline \multirow{3}{*}{ slr0737 } & \multirow{3}{*}{$\begin{array}{c}\text { Photosystem I } \\
\text { subunit II }\end{array}$} & IGQNPEPVTIK(pr)FSGK & 132 & 76.85 & 0.97 \\
\hline & & VYPSGEVQYLHPADGVFPEK(pr)VNEGR & 107 & 111.58 & 1 \\
\hline & & IQDYK(pr)IYR & 84 & 72.547 & 1 \\
\hline
\end{tabular}

C

Synechocystis sp. PCC 6803 Lyngbya sp. PCC 8106 Synechococcus sp. PCC 7002 Nostoc sp. PCC 7120 Guillardia theta Puillardia theta Thermosynechococcus elongatus BP-1 Prochlorococcus marinus Gloeobacter violaceus Cyanophora paradoxa Chlamydomonas reinhardtii Spinacia oleracea Solanum lycopersicum Bigelowiella natans $84 \quad 107$ 132 KIQDYKIYRV ‥ YPSGEVQY LHPADGVFPE KVNEGREAQG -EPVTIKFSG KAPYEV.... KIEDFKIYRI $\ldots$ YPNGEMEY LHPKDGVFPE KVNEGRDFYG -DPAKVKFSG KATYEV ... KITDYKIYRV ..FPSGETOF LYPLDGVPSE KVNEGREYKG -EPATLKFSG VAPYEA KITMYKIYAI - LPSGETTF IHPADGVPE KVHAGREKVR - PPSOVKFSG KATYDA KT - ISDYKIYRV - - FPNGEVQY LHPKDGVFPE KVNAGRASIN -NPINVKFTN KATYD ..... KINDYKIYRI - . FPDGETVL IHPKDGVFPE KVNKGREAVN -NPSQLKFTG KKPYD.... RIETSKIYRI - Y YPGGDREL LFPKDGVFSE KPNEGRLKEG - NPASLKFSG KKTYDA... KIRDSKIYRV $\cdots$ YPNGEQVL IFPMDGVPSE KSNPGREVVG -NPVDVKFTG KETFDV . . - ITDYKIYRV $\cdots Y$ Y SGEVOF LHPKDGVFPE KVNPGRVAVG .DPAKLKFKG OETFDSDL - LT PCFYRV - FPDGKVOY LHPADGVYPE KVNAGRVGAN -NPIKVKFSG RMMSPAEIIK-YOFYAV - FPSGEVOY LHPKDGVYPE KVMPGROGVG SPISVKFTG KO- PYDL.

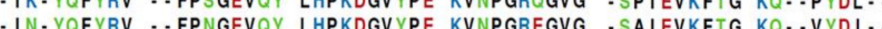
- ND. Conservation - IDGF-IYRI NQAKGGEVEY LHPKDGIYPE KVHPGAATSR SDPEKLKVGP PEDWDMEAYW
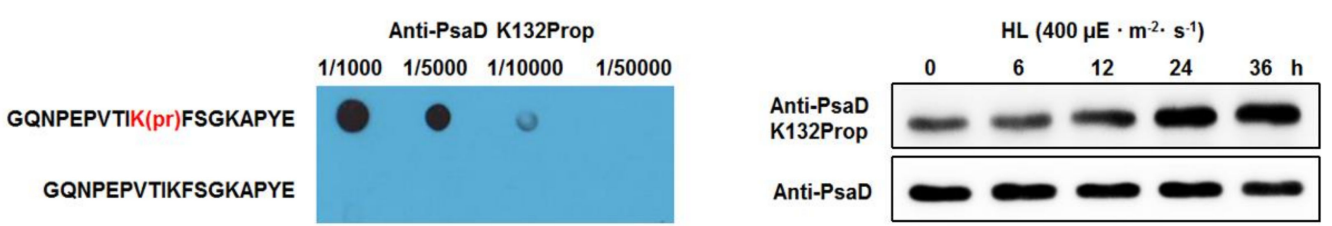

Figure 6. Identification of lysine propionylation in subunit II of photosystem I (PsaD). (A) Immunoblotting analysis of propionylation level of proteins from Synechocystis after exposure to high light intensity for $0,6,12,24$, and $36 \mathrm{~h}$. Coomassie blue staining was used for the loading control and western blotting analysis was performed using anti-propionyllysine antibody and anti-PsaD antibody. (B) List of identified propionylation sites of PsaD. (C) Conservation analysis of PsaD from different species (cyanobacteria, algae, and plants). The conserved propionylation sites were marked by the red arrow. (D) Immunoblotting analysis of Lys132 propionylation level of PsaD in Synechocystis after exposure to high light intensity for $0,6,12,24$, and $36 \mathrm{~h}$. The generated specific anti-Lys132 propionylation antibody was validated by dot blot analysis.

\section{Discussion}

Recently, we analyzed the lysine acetylome of Synechocystis and revealed previously unappreciated roles of lysine acetylation in the regulation of photosynthesis [31]. In this study, we report the first systematic study of lysine propionylation in a cyanobacterium model. This is, to the best of our knowledge, the first global survey of lysine propionylation in a photosynthetic organism. The identified propionylaton sites were present in proteins involved in various pathways and processes in Synechocystis. In particular, proteins in major metabolic and photosynthetic pathways are modified by propionylation. Since lysine propionylation has emerged as an essential regulatory post-translational modification and 
may affect multiple metabolic processes, our study provides a large number of putative regulatory modification sites in Synechocystis. Through western blot analysis using an anti-propionyllysine antibody, we found that propionylation occurred in diverse photosynthetic organisms, and that the levels of this modification changed in response to different stress treatments in Synechocystis, suggesting propionylation is a prevalent and regulatory PTM in photosynthetic organisms. Therefore, understanding the physiological functions of these propionylation sites would certainly be useful to elucidate the regulation of photosynthetic processes and metabolic networks in cyanobacteria and other photosynthetic organisms.

In the present study, a large number of proteins involved in carbon metabolism were propionylated. For example, slr2094 (FbpI), which encodes the fructose-1,6-biphosphatase (FBPase)/sedoheptulose-1,7-biphosphatase (SBPase) bifunctional enzyme, was found to be propionylated. FbpI can hydrolyze both fructose-1,6-bisphosphate (FBP) and sedoheptulose-1,7-bisphosphate (SBP) simultaneously in cyanobacteria [37]. It has been reported that FbpI is essential to sustain growth and has a vital role in photosynthetic carbon fixation and gluconeogenesis in cyanobacteria $[35,36,40,41]$. In addition, previous structure and biochemical analyses show that regulation of FbpI activity occurs at the structural level [37], and FbpI may adopt a unique regulatory mechanism that enables the enzyme to hydrolyze both FBP and SBP simultaneously [37]. It is conceivable that propionylation could have a more profound impact on protein structure and function compared to lysine acetylation, which regulates the activity of enzymes of central metabolic pathways in various eukaryotes and bacteria $[31,42,43]$. Consistent with this notion, our functional results suggest that lysine propionylation is likely to regulate $\mathrm{FbpI}$ activity. Thus, lysine propionylation could provide an additional layer to regulate the enzymatic activity of FbpI.

Increasing evidence shows that diverse PTM events are involved in the regulation of photosynthesis in cyanobacteria [31,44-47]. According to the dataset presented in this work, there exist many propionylated proteins in the photosynthetic pathway (Figure 5A), and the propionylation level of four photosynthetic proteins ( $\mathrm{PsaD}, \mathrm{PsbC}, \mathrm{PsbO}$, and $\mathrm{CpcB}$ ) were found to increase in response to HL conditions (Figure 5B). Notably, among the identified photosynthetic proteins, the propionylation level of PsaD (which is likely to interact with many different PSI subunits [48-53]), was suggested to be elevated under HL intensity (Figure 6A). PSI is a membrane chlorophyll-protein complex capable of light-induced electron transfer to soluble electron acceptors, resulting in the reduction of low-potential electron carriers (either ferredoxin (Fd) or flavodoxin [54]). PsaD, a subunit of Synechocystis PSI, is a conserved peripheral protein on the reducing side of PS I [55], and plays a critical role in the stability of PSI $[39,56]$. Specifically, the mutation of Lys132 decreases the stability of PSI and is harmful to the cell growth above $30{ }^{\circ} \mathrm{C}$ [39]. Lys132 is highly conserved, and plays an important role in maintaining an electrostatic stabilization of the $C$ terminus of PsaD [39]. To assess how modulation of protein propionylation affects its function, we examined the crystal structure of PSI complex from Synechocystis [57]. It showed that Lys132 in PsaD is adjacent to the acidic amino acids Glu32, Glu39, and Asp395 of PsaB within $5 \AA$, and may form intra-molecular electrostatic interactions with these acidic amino acids (Figure 7A). Thus, it is conceivable that propionylation in Lys132 may disrupt specific intra-molecular electrostatic interactions and decrease the structural stability of PsaD, thereby impairing the overall stability of PSI. 
A

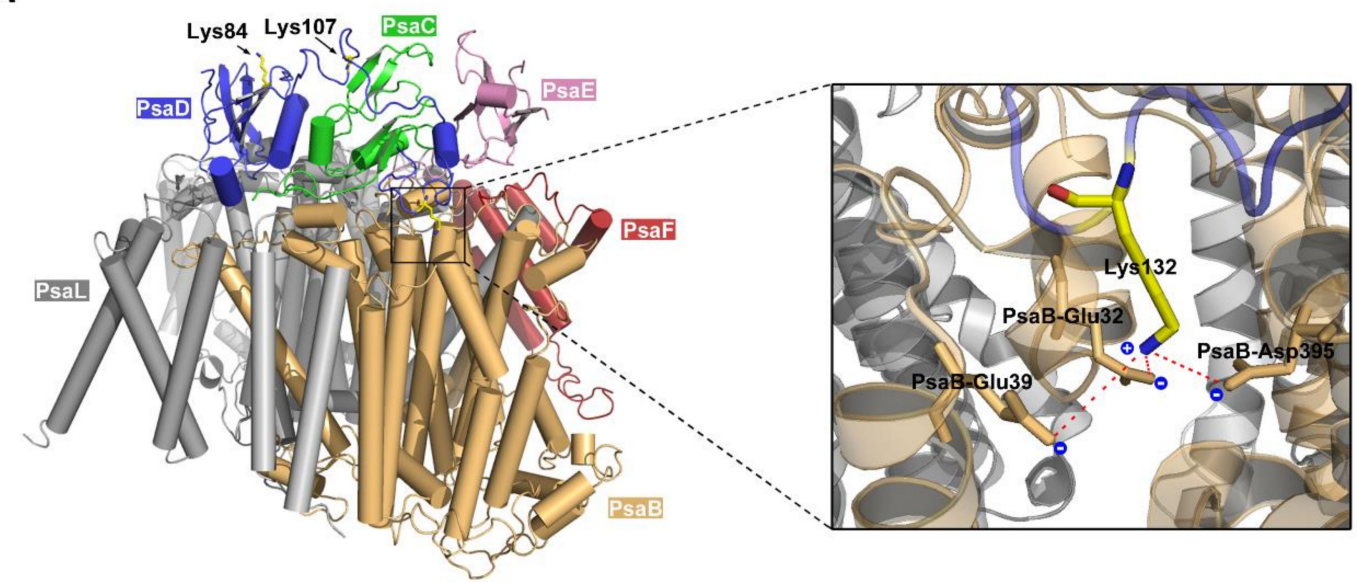

B

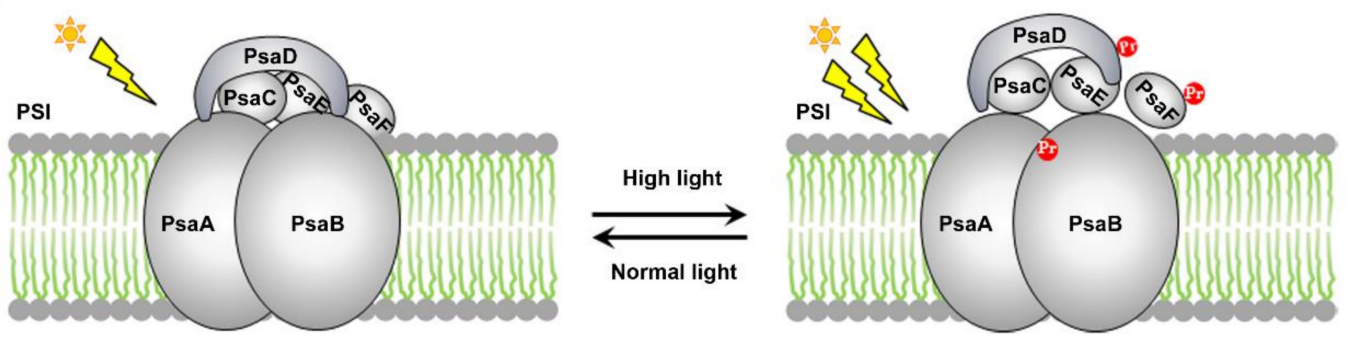

Figure 7. Analysis of the functional roles of PsaD propionylation. (A) The crystal structure of PsaD and other PSI subunits. The interactions between Lys132 side chain and the negatively charged amino acids are shown in detail. Lysine amine nitrogen of PsaD is within 5 A of the Glu32, Gly39, and Glu395 of PsaB. (B) Schematic summary of the proposed model of the role of PsaD propionylation during HL acclimation in Synechocystis. The Pr highlighted in red represents propionylation.

It is well-known that all photosynthetic organisms are often exposed to strong fluctuations in light intensity in their growth environments [58]. To cope with light fluctuations, cyanobacteria as well as plants have developed complex regulatory machinery to prevent their photosynthetic apparatus from high light conditions. For example, cyanobacteria acclimate to HL conditions by adjusting photosystem stoichiometry through a decrease of PSI abundance in thylakoid membranes $[59,60]$, and this decrease in PSI content is essential for Synechocystis to accommodate the continuous HL conditions in Synechocystis [61]. As PsaD has been proven to be a key protein in stabilizing the reducing side of PSI [56], and its integration considerably decreases the turnover of PSI [62], it is conceivable that the mechanism controlling PsaD level/modification is tightly associated with PSI abundance and HL response in Synechocystis. In light of our results and the published data, we propose a molecular model of propionylation during HL acclimation in Synechocystis (Figure 7B). Under HL intensity, multiple photosynthetic proteins were propionylated, such as the PSI-D subunit PsaD. Propionylation of PsaD reduced the electrostatic stabilization of its $C$ terminus and disrupted the electrostatic interaction between PsaD and other PSI subunits, which may lead to the decreased PSI stability and abundance. These coordinated responses can enable cyanobacteria to avoid absorbing excess light energy and escape from the photoinhibition and photodamage caused by HL intensity. Consistent with this model, down-regulation of the PSI abundance during the acclimation to HL has been observed in Synechocystis $[59,63,64]$, although the mechanism remains unclear. Therefore, reversible propionylation may be an important and previously unknown regulatory mechanism involved in the regulation of PSI abundance and HL acclimation in Synechocystis.

As one of the diverse types of PTM, protein propionylation competes with other forms of acylation —including acetylation, malonylation, crotonylation, succinylation, and butyrylation — for the same $\epsilon$-amino group of lysine residue [65]. Thus, it is likely that there exists a complicated interplay and 
crosstalk between lysine propionylation and other PTMs, which ultimately regulate protein functions and photosynthetic pathways. Revealing the combinatorial and hierarchical patterns of propionylation and other PTMs will be indispensable for us to understand metabolic and photosynthetic pathways in cyanobactria.

Overall, our results indicate that lysine propionylation is widespread in cyanobacteria and that it is likely to be an important regulatory mechanism in carbon metabolism and photosynthetic pathways in cyanobacteria. Future studies should be directed toward a better understanding of the underlying molecular mechanisms.

\section{Materials and Methods}

\subsection{Cell Culture and Protein Extraction}

The wild-type strain of Synechocystis was grown in BG-11 liquid medium bubbling with filtrated air at $30^{\circ} \mathrm{C}$ under continuous illumination at $40 \mu \mathrm{mol}$ photons $\mathrm{m}^{-2} \mathrm{~s}^{-1}$ [66]. Cells were grown under several conditions and harvested at different growth stages. For stress treatments, the cultures were grown to the exponential phase $\left(\mathrm{OD}_{730}=0.7 \sim 0.8\right)$ and immediately resuspended in medium deficient of nitrogen [67], iron [68], potassium [69], or A5 (trace metal elements). Briefly, cells in the exponential phase of growth were harvested by centrifugation, washed twice with nitrogen deficiency medium BG11 (lacking the specified nutrient), and immediately resuspended in medium BG11 without the specified nutrient: in Fe-free medium BG11 that added an Fe-binding chelator to the growth medium; in potassium-free medium BG11 that contained $\mathrm{Na}_{2} \mathrm{HPO}_{4}$ instead of $\mathrm{K}_{2} \mathrm{HPO}_{4}$; in nitrogen-free medium without nitrate $\left(\mathrm{NaNO}_{3}\right)$ ) or in A5-free medium $\mathrm{BG} 11$ (without the trace elements $\mathrm{H}_{3} \mathrm{BO}_{3}, \mathrm{MnCl}_{2} \bullet 4 \mathrm{H} 2 \mathrm{O}$, $\mathrm{ZnSO}_{4} \bullet 7 \mathrm{H}_{2} \mathrm{O}, \mathrm{Na}_{2} \mathrm{MoO}_{4} \bullet 2 \mathrm{H}_{2} \mathrm{O}, \mathrm{CuSO}_{4} \bullet 5 \mathrm{H}_{2} \mathrm{O}$, and $\left.\mathrm{Co}\left(\mathrm{NO}_{3}\right)_{2} \bullet 6 \mathrm{H}_{2} \mathrm{O}\right)$. For HL treatment, cells in the exponential growth phase $\left(\mathrm{OD}_{730} \approx 0.7 \sim 0.8\right)$ were harvested and adjusted to an $\mathrm{OD}_{730}$ of $\sim 0.3$ with fresh medium in tubes $(\varphi 40 \times 200 \mathrm{~mm})$ containing $100-\mathrm{mL}$ cultures that were exposed to HL $(400 \mu \mathrm{mol}$ photons $\mathrm{m}^{-2} \mathrm{~s}^{-1}$ ) for designated times. For high salt stress and heterotrophic conditions, cells grown to the exponential phase were transferred to fresh medium supplemented with $0.685 \mathrm{M} \mathrm{NaCl}$ or $5 \mathrm{mM}$ glucose. Cells with different treatments were harvested by centrifugation at $6000 \mathrm{~g}$ for $5 \mathrm{~min}$ at $4{ }^{\circ} \mathrm{C}$, washed twice with ice cold PBS buffer, and resuspended in ice-cold lysis buffer ( $20 \mathrm{mM}$ Tris- $\mathrm{Cl}, \mathrm{pH}$ 7.5, $150 \mathrm{mM} \mathrm{NaCl}, 1 \%$ Triton X-100, 50mM Nicotinamide, $\mathrm{pH} 7.5$ and $1 \times$ protease inhibitor cocktail). The mixture was then disrupted by sonication ( $2 \mathrm{~s}$ on, $2 \mathrm{~s}$ off) for $30 \mathrm{~min}$ on ice with an output of $135 \mathrm{~W}$ by a JY92-IIN sonicator (Ningbo Scientz Biotechnology Co., Ltd., Ningbo, China), and centrifuged at $5000 \times g$ for $30 \mathrm{~min}$ at $4{ }^{\circ} \mathrm{C}$. The supernatants were stored in aliquots at $-80^{\circ} \mathrm{C}$ until further use. Protein concentrations were measured using a BCA Protein Assay Kit (Beyotime, Jiangsu, China).

\subsection{In-Solution Trypsin Digestion and Immunoaffinity Enrichment of Propionylated Peptides}

Cell lysates were precipitated by using five volumes of ice-cold acetone, then washed twice with $80 \%(\mathrm{v} / \mathrm{v})$ ice-cold acetone. The precipitated proteins were redissolved in $50 \mathrm{mM}$ ammonium bicarbonate, then in-solution digested by trypsin, as previously described $[44,70]$. The propionylated peptides were enriched using anti-propionyl lysine antibody (PTM Biolabs Inc., Chicago, IL, USA), as previous described [30]. Briefly, tryptic peptides were resuspended in NETN buffer containing $50 \mathrm{mM}$ Tris- $\mathrm{HCl}$ (pH 8.0), $100 \mathrm{mM} \mathrm{NaCl}, 1 \mathrm{mM}$ EDTA, and 0.5\% Nonidet P-40, and centrifuged at $5000 \mathrm{~g}$ for 10 minutes. The supernatant was incubated with agarose beads conjugated with anti-propionyllysine antibody and the mixture was gently rotated for $6 \mathrm{~h}$ at $4{ }^{\circ} \mathrm{C}$. The beads were washed sequentially with NETN buffer (three times), ETN buffer (50 mM Tris-Cl, pH 8.0, $100 \mathrm{mM} \mathrm{NaCl}$, $1 \mathrm{mM}$ EDTA, twice), and water (once). The propionylated peptides were eluted by three washes with $1 \%$ trifluoroacetic acid. The resulting propionylated peptides were condensed in a vacuum centrifuge and desalted by self-packed $\mathrm{C}_{18}$ STAGE tips according to the manufacturer's instructions, prior to nano-HPLC-MS/MS analysis. 


\subsection{Nano-HPLC-MS/MS Analysis}

The enriched peptides were dissolved in the HPLC buffer A $(0.1 \%(\mathrm{v} / \mathrm{v})$ formic acid in water), and analyzed by online nanoflow LC-MS/MS using an easy nLC-1000 system (Thermo Fisher Scientific, Waltham, MA, USA) connected to a Q-Exactive (Thermo Fisher Scientific, Waltham, MA, USA) mass spectrometer. Briefly, samples were injected onto the analytical C18-nanocapillary LC column $(5 \mu \mathrm{m}$ particle size, $100 \AA$ A pore diameter) and eluted at a flow rate of $300 \mathrm{~nL} / \mathrm{min}$ with a 40 -min linear gradient of $6-90 \%$ solvent B $(98 \%$ ACN $/ 0.1 \%$ formic acid, $v / v)$. The peptides were then directly ionized and sprayed into a Q-Exactive mass spectrometer via a nanospray ion source. Mass spectrometer analysis was carried out in a data-dependent mode with full scans (350-1800 m/z) acquired using an Orbitrap mass analyzer at a mass resolution of 70,000 at $\mathrm{m} / \mathrm{z}=200$. Following every survey scan, up to 20 of the most intense precursor ions were picked for MS/MS fragmentation by higher-energy C-trap dissociation (HCD) with a normalized collision energy of $28 \%$. The dynamic exclusion duration was set to be $10 \mathrm{~s}$ with a repeat count of 1 and $\pm 10 \mathrm{ppm}$ exclusion window. The electrospray voltage applied was $2.0 \mathrm{kV}$. The automatic gain control (AGC) for full MS was set to $3 \times 10^{6}$ ions, with $5 \times 10^{4}$ ions for MS/MS, using ion injection times of 50 and $200 \mathrm{~ms}$, respectively. Internal calibration was carried out using lock mass at $\mathrm{m} / \mathrm{z} 445.120025$.

\subsection{Experimental Design and Statistical Rationale}

To identify as many propionylation events as possible in this work, we performed a series of preliminary experiments using small amount of Synechocystis proteins to find the best protocol, such as: the optimum amount of starting protein; the ratio of antibody to agarose and peptides; the incubation time of antibody, agarose, and peptides; and the optimum operating parameters of mass spectrometers. Based on the results of these preliminary experiments, we performed a global lysine propionylation analysis of Synechocystis using optimized experimental procedures as described in this manuscript. For the enrichment and motif analysis, a Benjamini-corrected statistical significance value (adjusted $p$ value) cutoff of 0.05 was used to control the family-wide false discovery rate.

\subsection{Data Analysis and Peptide Identification}

The MS/MS spectra were searched against the Synechocystis protein database from the Cyanobase database (http://genome.microbedb.jp/cyanobase/Synechocystis/, including 3672 protein sequences, released 2012) concatenated with a reverse decoy database and common contaminants by using MaxQuant software (version 1.3.0.5) [71]. The cleavage enzyme was specified as trypsin, and the maximum missed cleavage sites were set as 2 . The precursor and fragmented ion mass tolerances were 10 ppm and $0.02 \mathrm{Da}$, respectively. Carbamidomethylation (Cys) was specified as a fixed modification, while oxidation (Met), deamidation (Asn/Gln), propionylation (Lys), and acetylation (Protein N-terminal) were set as variable modifications. Minimum peptide length was set at six. The maximum false discovery rate (FDR) for modification site, peptide, and protein were specified as $1 \%$. All MS/MS spectra for propionylated peptides were manually inspected using criteria previously reported [24]. The identified peptides with C-terminal propionylation were discarded prior to bioinformatics analysis to improve the data quality.

\subsection{Bioinformatics Analysis}

All identified propionylated proteins were classified into biological process and molecular function class based on the Gene Ontology (GO) terms by Blast2GO software [72]. The subcellular localization of identified proteins was performed by the PSORTb program [73]. Functional enrichment analyses were carried out by DAVID for the GO term, KEGG (Kyoto Encyclopedia of Genes and Genomes) pathways, and protein family (PFAM) domains [74,75]. The protein-protein interaction (PPI) network of propionylated proteins were visualized by Cytoscape [76] using the interaction data from the Synechocystis PPI database (http://bioportal.kobic.kr/SynechoNET) [31,77]. Amino acid sequence motifs 
were analyzed using the pLogo web tool (version 1.2.0) [78]. The secondary structures around the propionylated lysines were predicted by using the NetSurfP tool [79]. The structure models were prepared from the available crystal structure via structural modeling using a SWISS-MODEL Server (http://swissmodel.expasy.org//SWISS-MODEL.html). The PyMOL Molecular Graphics System (version 1.7.2, http://www.pymol.org) was employed to present the structural results of this study. In our data, the corresponding $p$ value $<0.05$ was considered statistically significant. The lipoproteins and integral membrane proteins were analyzed by the LipoP 1.0 server [25] (http://www.cbs.dtu.dk/services/LipoP/) and THHMM server 2.0 [24] (http://www.cbs.dtu.dk/services/TMHMM/) as previously described [23].

\subsection{Production of Specific Antibodies against Synechocystis Proteins}

The generation of polyclonal antibodies against Synechocystis proteins was carried out by ABclonal Inc. (Wuhan, China). Briefly, to produce the polyclonal antibodies against PsbC (photosystem II CP43 protein), $\mathrm{CpcB}$ (phycocyanin beta subunit), and PsaD, full-length cDNA of these genes were amplified and cloned into the pGEX-4T expression vector (Pharmacia). The resulting plasmids were transformed into Escherichia coli strain BL21 (DE3) for overexpression. Cells growing logarithmically were treated with 1-mM isopropyl- $\beta$-D-thiogalactopyranoside (IPTG) for $4 \mathrm{~h}$ at $30^{\circ} \mathrm{C}$. The fusion proteins were then purified by performing His-tag affinity chromatography. For the polyclonal antibody against propionylated PsaD at lysine 132, a synthetically modified peptide of GQNPEPVTIK(pr)FSGKAPYE was used to generate the site-specific propionyllysine antibody, whereas the unmodified peptide of GQNPEPVTIKFSGKAPYE was used as control. Following purification of these antigens, immunization and sampling of the antisera from rabbit were performed by ABclonal according to standard operating procedures. The specificity of the generated antibodies was determined by the manufacturer using ELISA and western blotting.

\subsection{Immunoprecipitation and Western Blotting}

To further validate propionylated proteins, we performed immunoprecipitation and western blotting to analyze the Synechocystis proteins in vivo using the generated specific protein antibodies as previously described [30,31]. Briefly, Dynabeads Protein G (Invitrogen AS, Oslo, Norway) with specific protein antibody was incubated with whole cell lysates in PBS containing $0.02 \%$ Tween 20 by gentle rotation overnight at $4{ }^{\circ} \mathrm{C}$. The beads were then washed three times to remove the unbound proteins. Bound proteins were boiled in SDS loading buffer for $5 \mathrm{~min}$ then subjected to $12 \%$ SDS-PAGE and transferred to a polyvinylidene difluoride (PVDF) membrane for further western blotting analysis. The membrane was incubated with generated Synechocystis protein antibody or anti-propionyl lysine antibody (PTM Biolabs Inc., Chicago, IL) (1:2,000, in TBST/5\% BSA). The membrane was then washed three times with TBST buffer ( $25 \mathrm{mM}$ Tris- $\mathrm{HCl}, \mathrm{pH} 8.0,150 \mathrm{mM} \mathrm{NaCl}, 0.1 \%$ Tween 20 ) and incubated with horseradish peroxidase-conjugated goat antirabbit antibody (1:5000 dilutions) for $1 \mathrm{~h}$ at $37^{\circ} \mathrm{C}$. After being washed with TBST buffer, the membrane was visualized with enhanced chemiluminescence (ECL) immune-blotting detection reagents (Advansta, CA, USA). The density of each band was determined with a fluorescence scanner (ImageQuant TL, GE Healthcare). Densitometry analysis was performed via the ImageJ suite (http://rsbweb.nih.gov/ij/).

\subsection{Site-directed Mutagenesis and Purification of fructose-1,6-/sedoheptulose-1,7-bisphosphatase (FbpI)}

The full-length $f b p I$ gene (slr2094) was amplified by using Synechocystis genomic DNA as a template with the following primers: FbpI-sense (5'-GCTAGCGTGGACAGCACCCTCGGTT- $3^{\prime}$ ) and FbpI-antisense (5'-CTCGAGATGCAGTTGGATTACTTTGGGGCT-3'). The PCR amplicon was inserted into pMD18-T (Takara). The site-directed mutation of the $f b p I$ gene was introduced into the selected sites by PCR reaction and, subsequently, the mutagenesis was completely sequenced to confirm the presence of the site-directed mutation. Mutagenic primers were given below with the mutated base triplets underlined: FbpI-K156R-sense ( $5^{\prime}$-CCGAAAACCTGCGGATCCTCTCCGATTGCCTCAACCG-3'); FbpI-K156R-antisense (5'-TCCGCAGGTTTTCGGTGGCCGAT-3'); FbpI-K336R-sense (5'-TGCGG 
GAAAGCCCCAAAGTAATCCAAC-3'); FbpI-K336R-antisense (5'-GGCTTTCCCGCATATGGACAGTGT CTACAAAGCGGGCGG-3'). Next, the plasmids containing the wild-type or point-mutated fbpI genes were digested with NheI and XhoI, and the fragments were inserted into pET21b (Novagen), followed by transformation into E. coli BL21 (DE3) for protein expression.

The wild-type E. coli BL21 (DE3)/pET21b-fbpI and the site-directed mutants were cultured in $5 \mathrm{~mL}$ Luria-Bertani (LB) medium supplemented with ampicillin $(50 \mathrm{~g} / \mathrm{mL})$ overnight at $37^{\circ} \mathrm{C}$. The cultures were then transformed into fresh LB medium with ampicillin $(50 \mathrm{~g} / \mathrm{mL})$ at $37^{\circ} \mathrm{C}$ in shaking flasks to optical density at $600 \mathrm{~nm}$ of $0.4-0.6$. Cells were induced with $0.1 \mathrm{mM}$ isopropyl- $\beta$-D-1-thiogalactopyranoside (IPTG) at $16{ }^{\circ} \mathrm{C}$ for $12 \mathrm{~h}$. The cultures were harvested by centrifugation at $6000 \mathrm{rpm}$ for $5 \mathrm{~min}$ at $4{ }^{\circ} \mathrm{C}$. After being washed twice with ice-cold PBS, the pellets were resuspended in binding buffer $(20 \mathrm{mM}$ Tris- $\mathrm{HCl}(\mathrm{pH} 8.0), 500 \mathrm{mM} \mathrm{NaCl})$ and disrupted by high-pressure homogenizer with an output of $1500 \mathrm{~W}$ (1500 bar, JN-02C, JNBIO, Guangzhou, China). Cellular debris were removed by centrifugation at $8000 \times g$ for $30 \mathrm{~min}$ at $4{ }^{\circ} \mathrm{C}$, and the supernatants were loaded onto an affinity $\mathrm{Ni}^{2+}$ column (Qiagen Inc., Chatsworth, $\mathrm{CA}$ ) pre-equilibrated with the binding buffer. After the column was washed with washing buffer $(20 \mathrm{mM}$ Tris- $\mathrm{HCl}, \mathrm{pH} 8.0,500 \mathrm{mM}$ $\mathrm{NaCl}$, and $30 \mathrm{mM}$ imidazole or $60 \mathrm{mM}$ imidazole), the target protein was then eluted with elution buffer (20 mM Tris-HCl, pH 8.0, $500 \mathrm{mM} \mathrm{NaCl}$, and $100 \mathrm{mM}$ imidazole). The elution was desalted and concentrated using a 30,000 MWCO concentrator (Millipore) in storage buffer (20 mM Tris-HCl, pH 8.0, $50 \mathrm{mM} \mathrm{NaCl}$ ). Protein concentration was determined by a BCA protein assay (Beyotime, Jiangsu, China) and the purified proteins were analyzed by SDS-PAGE.

\subsection{Enzymatic Activity Assay}

The activity of purified $\mathrm{FbpI}$ and its mutants were determined by monitoring dihydronicotinamide adenine dinuclectide phosphate (NADPH) formation from NADP+, resulting in an absorbance increase at $340 \mathrm{~nm}$ as previously described [35]. Briefly, the purified protein was incubated with reaction buffer (10 mM MgCl, $100 \mathrm{mM}$ Tris- $\mathrm{HCl}$ (pH 8.0), $0.5 \mathrm{mM}$ EDTA, $0.4 \mathrm{mM} \mathrm{NADP}^{+}, 0.5 \mathrm{U} / \mathrm{mL}$ yeast glucose-6-phosphate dehydrogenase, and $1.5 \mathrm{U} / \mathrm{mL}$ yeast phosphoglucoisomerase). Reactions were pre-incubated at $30^{\circ} \mathrm{C}$ for $5 \mathrm{~min}$, then the fructose 1,6-phosphate was immediately added to a final concentration of $0.2 \mathrm{mM}$. After $15 \mathrm{~min}$ incubation at $30^{\circ} \mathrm{C}$, reactions were measured by monitoring the absorbance at $340 \mathrm{~nm}$ using SpectraMax M5 (Molecular devices, USA). The reaction mixture without enzyme served as a blank. Enzymatic activity was given as $\mu \mathrm{mol} \mathrm{min}^{-1}$ (mg protein) ${ }^{-1}$.

Supplementary Materials: Supplementary materials can be found at http://www.mdpi.com/1422-0067/20/19/ 4792/s1.

Author Contributions: Conceptualization, F.G.; methodology, F.G.; validation, H.H.; formal analysis, M.Y., F.G., and H.H.; investigation, M.Y. and H.H.; resources, F.G.; data curation, F.G.; writing-original draft preparation, M.Y. and F.G.; writing-review and editing, F.G.; visualization, F.G., M.Y., and H.H.; supervision, F.G.; project administration, F.G.; funding acquisition, F.G.

Funding: This research was funded by the National Natural Science Foundation of China (grant Number 31570829), the Strategic Priority Research Program of the Chinese Academy of Sciences (grant number XDB14030202).

Conflicts of Interest: The authors declare no conflict of interest. 


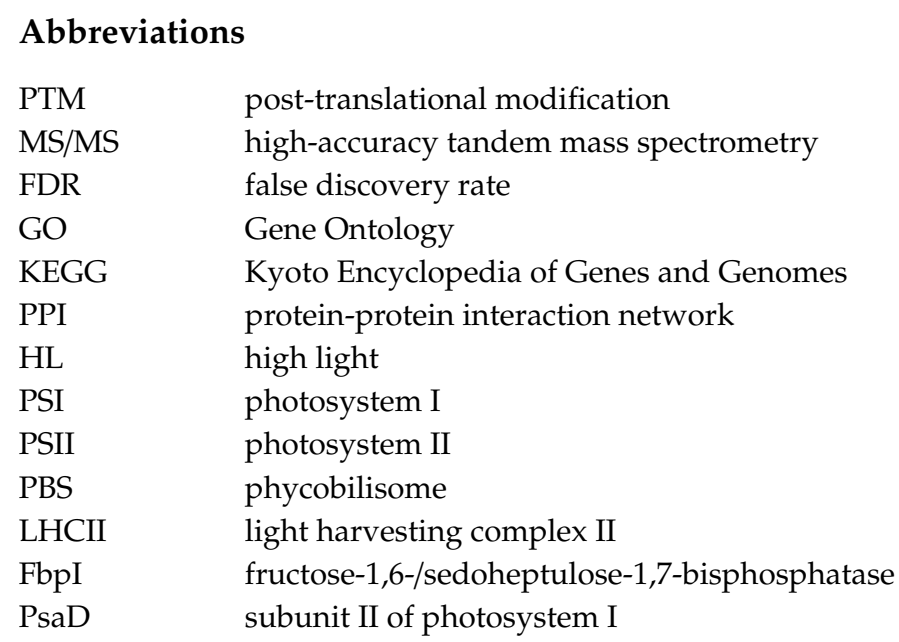

\section{References}

1. Cheng, Z.; Tang, Y.; Chen, Y.; Kim, S.; Liu, H.; Li, S.S.; Gu, W.; Zhao, Y. Molecular characterization of propionyllysines in non-histone proteins. Mol. Cell. Proteomics 2009, 8, 45-52. [CrossRef] [PubMed]

2. Chen, Y.; Sprung, R.; Tang, Y.; Ball, H.; Sangras, B.; Kim, S.C.; Falck, J.R.; Peng, J.; Gu, W.; Zhao, Y. Lysine propionylation and butyrylation are novel post-translational modifications in histones. Mol. Cell. Proteomics 2007, 6, 812-819. [CrossRef] [PubMed]

3. Okanishi, H.; Kim, K.; Masui, R.; Kuramitsu, S. Lysine propionylation is a prevalent post-translational modification in Thermus thermophilus. Mol. Cell. Proteomics 2014, 13, 2382-2398. [CrossRef] [PubMed]

4. Singhal, A.; Arora, G.; Virmani, R.; Kundu, P.; Khanna, T.; Sajid, A.; Misra, R.; Joshi, J.; Yadav, V.; Samanta, S.; et al. Systematic Analysis of Mycobacterial Acylation Reveals First Example of Acylation-mediated Regulation of Enzyme Activity of a Bacterial Phosphatase. J. Biol. Chem. 2015, 290, 26218-26234. [CrossRef] [PubMed]

5. Zhang, K.; Chen, Y.; Zhang, Z.; Zhao, Y. Identification and verification of lysine propionylation and butyrylation in yeast core histones using PTMap software. J. Proteome Res. 2009, 8, 900-906. [CrossRef] [PubMed]

6. Liu, B.; Lin, Y.; Darwanto, A.; Song, X.; Xu, G.; Zhang, K. Identification and characterization of propionylation at histone H3 lysine 23 in mammalian cells. J. Biol. Chem. 2009, 284, 32288-32295. [CrossRef]

7. Fritz, K.S.; Green, M.F.; Petersen, D.R.; Hirschey, M.D. Ethanol metabolism modifies hepatic protein acylation in mice. PLoS One 2013, 8, e75868. [CrossRef]

8. Garrity, J.; Gardner, J.G.; Hawse, W.; Wolberger, C.; Escalante-Semerena, J.C. N-lysine propionylation controls the activity of propionyl-CoA synthetase. J. Biol. Chem. 2007, 282, 30239-30245. [CrossRef]

9. Abed, R.M.; Dobretsov, S.; Sudesh, K. Applications of cyanobacteria in biotechnology. J. Appl. Microbiol. 2009, 106, 1-12. [CrossRef]

10. Nozzi, N.E.; Oliver, J.W.; Atsumi, S. Cyanobacteria as a Platform for Biofuel Production. Front. Bioeng. Biotechnol. 2013, 1, 7. [CrossRef]

11. Chellamuthu, V.R.; Alva, V.; Forchhammer, K. From cyanobacteria to plants: conservation of PII functions during plastid evolution. Planta 2013, 237, 451-462. [CrossRef]

12. Field, C.B.; Behrenfeld, M.J.; Randerson, J.T.; Falkowski, P. Primary production of the biosphere: integrating terrestrial and oceanic components. Science 1998, 281, 237-240. [CrossRef]

13. Kaneko, T.; Sato, S.; Kotani, H.; Tanaka, A.; Asamizu, E.; Nakamura, Y.; Miyajima, N.; Hirosawa, M.; Sugiura, M.; Sasamoto, S.; et al. Sequence analysis of the genome of the unicellular cyanobacterium Synechocystis sp. strain PCC6803. II. Sequence determination of the entire genome and assignment of potential protein-coding regions. DNA Res. 1996, 3, 109-136. [CrossRef]

14. Williams, J.G.K. Construction of specific mutations in photosystem II photosynthetic reaction center by genetic engineering methods in Synechocystis 6803. Method. Enzymol. 1988, 167, 766-778.

15. Gao, L.; Wang, J.; Ge, H.; Fang, L.; Zhang, Y.; Huang, X.; Wang, Y. Toward the complete proteome of Synechocystis sp. PCC 6803. Photosynth. Res. 2015, 126, 203-219. [CrossRef] 
16. Noctor, G.; Dutilleul, C.; De Paepe, R.; Foyer, C.H. Use of mitochondrial electron transport mutants to evaluate the effects of redox state on photosynthesis, stress tolerance and the integration of carbon/nitrogen metabolism. J. Exp. Bot. 2004, 55, 49-57. [CrossRef]

17. Padmasree, K.; Padmavathi, L.; Raghavendra, A.S. Essentiality of mitochondrial oxidative metabolism for photosynthesis: optimization of carbon assimilation and protection against photoinhibition. Crit. Rev. Biochem. Mol. Biol. 2002, 37, 71-119. [CrossRef]

18. Tan, X.; Yao, L.; Gao, Q.; Wang, W.; Qi, F.; Lu, X. Photosynthesis driven conversion of carbon dioxide to fatty alcohols and hydrocarbons in cyanobacteria. Metab. Eng. 2011, 13, 169-176. [CrossRef]

19. Singh, A.K.; Elvitigala, T.; Bhattacharyya-Pakrasi, M.; Aurora, R.; Ghosh, B.; Pakrasi, H.B. Integration of carbon and nitrogen metabolism with energy production is crucial to light acclimation in the cyanobacterium Synechocystis. Plant Physiol. 2008, 148, 467-478. [CrossRef]

20. Wegener, K.M.; Singh, A.K.; Jacobs, J.M.; Elvitigala, T.; Welsh, E.A.; Keren, N.; Gritsenko, M.A.; Ghosh, B.K.; Camp, D.G., 2nd; Smith, R.D.; et al. Global proteomics reveal an atypical strategy for carbon/nitrogen assimilation by a cyanobacterium under diverse environmental perturbations. Mol. Cell. Proteomics 2010, 9, 2678-2689. [CrossRef]

21. Chen, Y.; Kwon, S.W.; Kim, S.C.; Zhao, Y. Integrated approach for manual evaluation of peptides identified by searching protein sequence databases with tandem mass spectra. J. Proteome Res. 2005, 4, 998-1005. [CrossRef]

22. Macek, B.; Gnad, F.; Soufi, B.; Kumar, C.; Olsen, J.V.; Mijakovic, I.; Mann, M. Phosphoproteome analysis of E. coli reveals evolutionary conservation of bacterial Ser/Thr/Tyr phosphorylation. Mol. Cell. Proteomics 2008, 7, 299-307. [CrossRef]

23. Liberton, M.; Saha, R.; Jacobs, J.M.; Nguyen, A.Y.; Gritsenko, M.A.; Smith, R.D.; Koppenaal, D.W.; Pakrasi, H.B. Global proteomic analysis reveals an exclusive role of thylakoid membranes in bioenergetics of a model cyanobacterium. Mol. Cell. Proteomics 2016, 15, 2021-2032. [CrossRef]

24. Krogh, A.; Larsson, B.; von Heijne, G.; Sonnhammer, E.L. Predicting transmembrane protein topology with a hidden Markov model: application to complete genomes. J. Mol. Biol. 2001, 305, 567-580. [CrossRef]

25. Juncker, A.S.; Willenbrock, H.; Von Heijne, G.; Brunak, S.; Nielsen, H.; Krogh, A. Prediction of lipoprotein signal peptides in Gram-negative bacteria. Protein Sci. 2003, 12, 1652-1662. [CrossRef]

26. Tyystjarvi, T.; Herranen, M.; Aro, E.M. Regulation of translation elongation in cyanobacteria: Membrane targeting of the ribosome nascent-chain complexes controls the synthesis of D1 protein. Mol. Microbiol. 2001, 40, 476-484. [CrossRef]

27. Tyystjarvi, T.; Sirpio, S.; Aro, E.M. Post-transcriptional regulation of the psbA gene family in the cyanobacterium Synechococcus sp. PCC 7942. FEBS Lett. 2004, 576, 211-215. [CrossRef]

28. Allakhverdiev, S.I.; Nishiyama, Y.; Takahashi, S.; Miyairi, S.; Suzuki, I.; Murata, N. Systematic analysis of the relation of electron transport and ATP synthesis to the photodamage and repair of photosystem II in Synechocystis. Plant Physiol. 2005, 137, 263-273. [CrossRef]

29. Nishiyama, Y.; Allakhverdiev, S.I.; Murata, N. Protein synthesis is the primary target of reactive oxygen species in the photoinhibition of photosystem II. Physiol. Plant. 2011, 142, 35-46. [CrossRef]

30. Yang, M.; Wang, Y.; Chen, Y.; Cheng, Z.; Gu, J.; Deng, J.; Bi, L.; Chen, C.; Mo, R.; Wang, X.; et al. Succinylome analysis reveals the involvement of lysine succinylation in metabolism in pathogenic Mycobacterium tuberculosis. Mol. Cell. Proteomics 2015, 14, 796-811. [CrossRef]

31. Mo, R.; Yang, M.; Chen, Z.; Cheng, Z.; Yi, X.; Li, C.; He, C.; Xiong, Q.; Chen, H.; Wang, Q.; et al. Acetylome analysis reveals the involvement of lysine acetylation in photosynthesis and carbon metabolism in the model cyanobacterium Synechocystis sp. PCC 6803. J. Proteome Res. 2015, 14, 1275-1286. [CrossRef]

32. Sato, S.; Shimoda, Y.; Muraki, A.; Kohara, M.; Nakamura, Y.; Tabata, S. A large-scale protein protein interaction analysis in Synechocystis sp. PCC6803. DNA Res. 2007, 14, 207-216. [CrossRef]

33. Yan, C.; Xu, X. Bifunctional enzyme FBPase/SBPase is essential for photoautotrophic growth in cyanobacterium Synechocystis sp. PCC 6803. Prog. Nat. Sci. 2008, 18, 149-153. [CrossRef]

34. Tamoi, M.; Takeda, T.; Shigeoka, S. Functional Analysis of Fructose-1,6-Bisphosphatase Isozymes (fbp-I and fbp-II Gene Products) in Cyanobacteria. Plant Cell Physiol. 1999, 40, 257-261. [CrossRef] 
35. Tamoi, M.; Murakami, A.; Takeda, T.; Shigeoka, S. Acquisition of a new type of fructose-1,6-bisphosphatase with resistance to hydrogen peroxide in cyanobacteria: molecular characterization of the enzyme from Synechocystis PCC 6803. Biochim. Biophys. Acta 1998, 1383, 232-244. [CrossRef]

36. Tamoi, M.; Ishikawa, T.; Takeda, T.; Shigeoka, S. Molecular characterization and resistance to hydrogen peroxide of two fructose-1,6-bisphosphatases from Synechococcus PCC 7942. Arch. Biochem. Biophys. 1996, 334, 27-36. [CrossRef]

37. Feng, L.; Sun, Y.; Deng, H.; Li, D.; Wan, J.; Wang, X.; Wang, W.; Liao, X.; Ren, Y.; Hu, X. Structural and biochemical characterization of fructose-1,6/sedoheptulose-1,7-bisphosphatase from the cyanobacterium Synechocystis strain 6803. FEBS J. 2014, 281, 916-926. [CrossRef]

38. Cotton, C.A.; Kabasakal, B.V.; Miah, N.A.; Murray, J.W. Structure of the dual-function fructose-1,6/sedoheptulose-1,7-bisphosphatase from Thermosynechococcus elongatus bound with sedoheptulose-7-phosphate. Acta Crystallogr. F Struct. Biol. Commun. 2015, 71, 1341-1345. [CrossRef]

39. Lagoutte, B.; Hanley, J.; Bottin, H. Multiple functions for the $C$ terminus of the PsaD subunit in the cyanobacterial photosystem I complex. Plant Physiol. 2001, 126, 307-316. [CrossRef]

40. Ogawa, T.; Tamoi, M.; Kimura, A.; Mine, A.; Sakuyama, H.; Yoshida, E.; Maruta, T.; Suzuki, K.; Ishikawa, T.; Shigeoka, S. Enhancement of photosynthetic capacity in Euglena gracilis by expression of cyanobacterial fructose-1,6-/sedoheptulose-1,7-bisphosphatase leads to increases in biomass and wax ester production. Biotechnol. Biofuels 2015, 8, 80. [CrossRef]

41. Tamoi, M.; Nagaoka, M.; Miyagawa, Y.; Shigeoka, S. Contribution of fructose-1,6-bisphosphatase and sedoheptulose-1,7-bisphosphatase to the photosynthetic rate and carbon flow in the Calvin cycle in transgenic plants. Plant Cell Physiol. 2006, 47, 380-390. [CrossRef]

42. Liu, F.; Yang, M.; Wang, X.; Yang, S.; Gu, J.; Zhou, J.; Zhang, X.E.; Deng, J.; Ge, F. Acetylome analysis reveals diverse functions of lysine acetylation in Mycobacterium tuberculosis. Mol. Cell. Proteomics 2014, 13, 3352-3366. [CrossRef]

43. Zhao, S.; Xu, W.; Jiang, W.; Yu, W.; Lin, Y.; Zhang, T.; Yao, J.; Zhou, L.; Zeng, Y.; Li, H.; et al. Regulation of cellular metabolism by protein lysine acetylation. Science 2010, 327, 1000-1004. [CrossRef]

44. Yang, M.K.; Qiao, Z.X.; Zhang, W.Y.; Xiong, Q.; Zhang, J.; Li, T.; Ge, F.; Zhao, J.D. Global phosphoproteomic analysis reveals diverse functions of serine/threonine/tyrosine phosphorylation in the model cyanobacterium Synechococcus sp. strain PCC 7002. J. Proteome Res. 2013, 12, 1909-1923. [CrossRef]

45. Xiong, Q.; Chen, Z.; Ge, F. Proteomic analysis of post translational modifications in cyanobacteria. J. Proteomics 2016, 134, 57-64. [CrossRef]

46. Chen, Z.; Zhan, J.; Chen, Y.; Yang, M.; He, C.; Ge, F.; Wang, Q. Effects of Phosphorylation of beta Subunits of Phycocyanins on State Transition in the Model Cyanobacterium Synechocystis sp. PCC 6803. Plant Cell Physiol. 2015, 56, 1997-2013. [CrossRef]

47. Zhang, C.C.; Jang, J.; Sakr, S.; Wang, L. Protein phosphorylation on Ser, Thr and Tyr residues in cyanobacteria. J. Mol. Microbiol. Biotechnol. 2005, 9, 154-166. [CrossRef]

48. Lelong, C.; Setif, P.; Lagoutte, B.; Bottin, H. Identification of the Amino-Acids Involved in the Functional Interaction between Photosystem-I and Ferredoxin from Synechocystis sp. PCC 6803 by Chemical Cross-Linking. J Biol Chem 1994, 269, 10034-10039.

49. Mannan, R.M.; Pakrasi, H.B.; Sonoike, K. The Psac Protein Is Necessary for the Stable Association of the Psad, Psae, and Psal Proteins in the Photosystem-I Complex - Analysis of a Cyanobacterial Mutant Strain. Arch Biochem Biophys 1994, 315, 68-73. [CrossRef]

50. Xu, Q.; Armbrust, T.S.; Guikema, J.A.; Chitnis, P.R. Organization of Photosystem-I Polypeptides - a Structural Interaction between the Psad and Psal Subunits. Plant Physiol 1994, 106, 1057-1063. [CrossRef]

51. Yu, J.P.; Smart, L.B.; Jung, Y.S.; Golbeck, J.; Mcintosh, L. Absence of Psac Subunit Allows Assembly of Photosystem-I Core but Prevents the Binding of Psad and Psae in Synechocystis sp. PCC 6803. Plant Mol Biol 1995, 29, 331-342. [CrossRef]

52. Chitnis, V.P.; Jung, Y.S.; Albee, L.; Golbeck, J.H.; Chitnis, P.R. Mutational analysis of photosystem I polypeptides - Role of PsaD and the Lysyl 106 residue in the reductase activity of photosystem I. J Biol Chem 1996, 271, 11772-11780. [CrossRef]

53. Sun, J.; Xu, Q.; Chitnis, V.P.; Jin, P.; Chitnis, P.R. Topography of the photosystem I core proteins of the cyanobacterium Synechocystis sp. PCC 6803. J Biol Chem 1997, 272, 21793-21802. [CrossRef] 
54. Yang, H.; Liu, J.; Wen, X.; Lu, C. Molecular mechanism of photosystem I assembly in oxygenic organisms. Biochim. Biophys. Acta 2015, 1847, 838-848. [CrossRef]

55. Minai, L.; Fish, A.; Darash-Yahana, M.; Verchovsky, L.; Nechushtai, R. The assembly of the PsaD subunit into the membranal photosystem I complex occurs via an exchange mechanism. Biochemistry 2001, 40, 12754-12760. [CrossRef]

56. Jin, P.; Sun, J.; Chitnis, P.R. Structural features and assembly of the soluble overexpressed PsaD subunit of photosystem I. Biochim. Biophys. Acta 1999, 1410, 7-18. [CrossRef]

57. Mazor, Y.; Nataf, D.; Toporik, H.; Nelson, N. Crystal structures of virus-like photosystem I complexes from the mesophilic cyanobacterium Synechocystis sp. PCC 6803. eLife 2013, 3, e01496. [CrossRef]

58. Allahverdiyeva, Y.; Suorsa, M.; Tikkanen, M.; Aro, E.M. Photoprotection of photosystems in fluctuating light intensities. J. Exp. Bot. 2015, 66, 2427-2436. [CrossRef]

59. Kopecna, J.; Komenda, J.; Bucinska, L.; Sobotka, R. Long-term acclimation of the cyanobacterium Synechocystis sp. PCC 6803 to high light is accompanied by an enhanced production of chlorophyll that is preferentially channeled to trimeric photosystem I. Plant Physiol. 2012, 160, 2239-2250. [CrossRef]

60. Muramatsu, M.; Sonoike, K.; Hihara, Y. Mechanism of downregulation of photosystem I content under high-light conditions in the cyanobacterium Synechocystis sp. PCC 6803. Microbiology 2009, 155, 989-996. [CrossRef]

61. Muramatsu, M.; Hihara, Y. Acclimation to high-light conditions in cyanobacteria: from gene expression to physiological responses. J. Plant Res. 2012, 125, 11-39. [CrossRef]

62. Chitnis, V.P.; Ke, A.; Chitnis, P.R. The PsaD subunit of photosystem I. Mutations in the basic domain reduce the level of PsaD in the membranes. Plant Physiol. 1997, 115, 1699-1705. [CrossRef]

63. Hihara, Y.; Sonoike, K.; Ikeuchi, M. A novel gene, pmgA, specifically regulates photosystem stoichiometry in the cyanobacterium Synechocystis species PCC 6803 in response to high light. Plant Physiol. 1998, 117, 1205-1216. [CrossRef]

64. Sonoike, K.; Hihara, Y.; Ikeuchi, M. Physiological significance of the regulation of photosystem stoichiometry upon high light acclimation of Synechocystis sp. PCC 6803. Plant Cell Physiol. 2001, 42, 379-384. [CrossRef]

65. Lin, H.; Su, X.; He, B. Protein lysine acylation and cysteine succination by intermediates of energy metabolism. ACS Chem. Biol. 2012, 7, 947-960. [CrossRef]

66. Stanier, R.Y.; Kunisawa, R.; Mandel, M.; Cohen-Bazire, G. Purification and properties of unicellular blue-green algae (order Chroococcales). Bacteriol. Rev. 1971, 35, 171-205.

67. Schlebusch, M.; Forchhammer, K. Requirement of the nitrogen starvation-induced protein S110783 for polyhydroxybutyrate accumulation in Synechocystis sp. strain PCC 6803. Appl. Environ. Microbiol. 2010, 76, 6101-6107. [CrossRef]

68. Krynicka, V.; Tichy, M.; Krafl, J.; Yu, J.; Kana, R.; Boehm, M.; Nixon, P.J.; Komenda, J. Two essential FtsH proteases control the level of the Fur repressor during iron deficiency in the cyanobacterium Synechocystis sp. PCC 6803. Mol. Microbiol. 2014, 94, 609-624. [CrossRef]

69. Berry, S.; Esper, B.; Karandashova, I.; Teuber, M.; Elanskaya, I.; Rogner, M.; Hagemann, M. Potassium uptake in the unicellular cyanobacterium Synechocystis sp. strain PCC 6803 mainly depends on a Ktr-like system encoded by slr1509 (ntpJ). FEBS Lett. 2003, 548, 53-58. [CrossRef]

70. Yang, M.K.; Yang, Y.H.; Chen, Z.; Zhang, J.; Lin, Y.; Wang, Y.; Xiong, Q.; Li, T.; Ge, F.; Bryant, D.A.; et al. Proteogenomic analysis and global discovery of posttranslational modifications in prokaryotes. Proc. Natl. Acad. Sci. U.S.A. 2014, 111, E5633-E5642. [CrossRef]

71. Cox, J.; Mann, M. MaxQuant enables high peptide identification rates, individualized p.p.b.-range mass accuracies and proteome-wide protein quantification. Nat. Biotechnol. 2008, 26, 1367-1372. [CrossRef]

72. Conesa, A.; Gotz, S. Blast2GO: A comprehensive suite for functional analysis in plant genomics. Int. J. Plant Genomics 2008, 2008, 619832. [CrossRef]

73. Yu, N.Y.; Wagner, J.R.; Laird, M.R.; Melli, G.; Rey, S.; Lo, R.; Dao, P.; Sahinalp, S.C.; Ester, M.; Foster, L.J.; et al. PSORTb 3.0: improved protein subcellular localization prediction with refined localization subcategories and predictive capabilities for all prokaryotes. Bioinformatics 2010, 26, 1608-1615. [CrossRef]

74. Huang da, W.; Sherman, B.T.; Lempicki, R.A. Systematic and integrative analysis of large gene lists using DAVID bioinformatics resources. Nat. Protoc. 2009, 4, 44-57. [CrossRef] 
75. Huang da, W.; Sherman, B.T.; Lempicki, R.A. Bioinformatics enrichment tools: paths toward the comprehensive functional analysis of large gene lists. Nucleic Acids Res. 2009, 37, 1-13. [CrossRef]

76. Shannon, P.; Markiel, A.; Ozier, O.; Baliga, N.S.; Wang, J.T.; Ramage, D.; Amin, N.; Schwikowski, B.; Ideker, T. Cytoscape: a software environment for integrated models of biomolecular interaction networks. Genome Res. 2003, 13, 2498-2504. [CrossRef]

77. Kim, W.Y.; Kang, S.; Kim, B.C.; Oh, J.; Cho, S.; Bhak, J.; Choi, J.S. SynechoNET: integrated protein-protein interaction database of a model cyanobacterium Synechocystis sp. PCC 6803. BMC Bioinformatics 2008, 9 (Suppl 1), S20. [CrossRef]

78. O'Shea, J.P.; Chou, M.F.; Quader, S.A.; Ryan, J.K.; Church, G.M.; Schwartz, D. pLogo: a probabilistic approach to visualizing sequence motifs. Nat. Methods 2013, 10, 1211-1212. [CrossRef]

79. Petersen, B.; Petersen, T.N.; Andersen, P.; Nielsen, M.; Lundegaard, C. A generic method for assignment of reliability scores applied to solvent accessibility predictions. BMC Struct. Biol. 2009, 9, 51. [CrossRef]

(C) 2019 by the authors. Licensee MDPI, Basel, Switzerland. This article is an open access article distributed under the terms and conditions of the Creative Commons Attribution (CC BY) license (http://creativecommons.org/licenses/by/4.0/). 